University of Wollongong

Research Online

Faculty of Science, Medicine and Health -

Papers: Part B

Faculty of Science, Medicine and Health

$1-1-2020$

\title{
UV-B and Drought Stress Influenced Growth and Cellular Compounds of Two Cultivars of Phaseolus vulgaris L. (Fabaceae)
}

Deborah Santos

Marcelo Ferreira

Tamara Matos

Wilton Sala-Carvalho

Fernanda Anselmo-Moreira

See next page for additional authors

Follow this and additional works at: https://ro.uow.edu.au/smhpapers1

Publication Details Citation

Santos, D., Ferreira, M., Matos, T., Sala-Carvalho, W., Anselmo-Moreira, F., Roma, L., Carvalho, J., PenaHidalgo, M., French, K., Waterman, M. J., Robinson, S. A., \& Furlan, C. (2020). UV-B and Drought Stress Influenced Growth and Cellular Compounds of Two Cultivars of Phaseolus vulgaris L. (Fabaceae). Faculty of Science, Medicine and Health - Papers: Part B. Retrieved from https://ro.uow.edu.au/smhpapers1/1587 


\title{
UV-B and Drought Stress Influenced Growth and Cellular Compounds of Two Cultivars of Phaseolus vulgaris L. (Fabaceae)
}

\author{
Abstract \\ (c) 2020 American Society for Photobiology Combined enhanced UV-B radiation and drought may induce \\ different morphological and physiological alterations in plants than either abiotic stress alone. We \\ evaluated morphology, biomass, and primary and secondary metabolism changes in seedlings of two \\ common bean cultivars, IAC Imperador (drought-resistant) and IAC Milênio. To test the hypothesis that \\ cultivars responded differently to combined stresses in a controlled environment, seedlings of the \\ examined been cultivars were exposed to UV-B and/or drought treatments for three weeks. The cultivars \\ behaved differently, especially to the drought treatment, suggesting that they use different mechanisms to \\ cope with unfavorable environmental conditions. IAC Imperador showed a stronger protective response, \\ modifying wax composition and primary metabolism, and improving its resistance to UV-B radiation. For \\ IAC Imperador, the accumulation of cuticular wax and alkane was higher under combined stress but \\ production of primary alcohols was reduced, suggesting a possible fatty acyl switch. Root/shoot length \\ and biomass ratios increased in both cultivars, particularly for the combined stress, indicating a common \\ plant response. We show that these two bean cultivars responded more strongly to UV-B and combined \\ stress than drought alone as evident in changes to their chemistry and biology. This shows the \\ importance of investigating plant morphological and physiological responses to combined stress.

\section{Publication Details} \\ Santos, D., Ferreira, M., Matos, T., Sala-Carvalho, W., Anselmo-Moreira, F., Roma, L., Carvalho, J., Pena- \\ Hidalgo, M., French, K., Waterman, M., Robinson, S. \& Furlan, C. (2020). UV-B and Drought Stress \\ Influenced Growth and Cellular Compounds of Two Cultivars of Phaseolus vulgaris L. (Fabaceae). \\ Photochemistry and Photobiology,

\section{Authors} \\ Deborah Santos, Marcelo Ferreira, Tamara Matos, Wilton Sala-Carvalho, Fernanda Anselmo-Moreira, \\ Lucas Roma, Juliana Carvalho, Miguel Pena-Hidalgo, Kris French, Melinda J. Waterman, Sharon A. \\ Robinson, and Claudia Furlan
}




\section{Photochemistry and Photobiology}

\section{UV-B and Drought Stress Influenced Growth and Cellular Compounds of Two Cultivars of Phaseolus vulgaris L. (Fabaceae)}

\begin{tabular}{|r|l|}
\hline Journal: & Photochemistry and Photobiology \\
\hline Manuscript ID & PHP-2020-02-RA-0035.R3 \\
\hline Wiley - Manuscript type: & Research Article \\
\hline Dute Submitted by the & 22-Jul-2020 \\
\hline Complete List of Authors: & $\begin{array}{l}\text { Santos, Deborah; University of Sao Paulo, Botany } \\
\text { Ferreira, Marcelo; University of Sao Paulo, Botany } \\
\text { Matos, Tamara; University of Sao Paulo, Botany } \\
\text { Sala-Carvalho, Wilton; University of Sao Paulo, Botany } \\
\text { Anselmo-Moreira, Fernanda; University of Sao Paulo, Botany } \\
\text { Roma, Lucas; University of Sao Paulo, Botany } \\
\text { Carvalho, Juliana; University of Sao Paulo, Botany } \\
\text { Peña-Hidalgo, Miguel; University of Sao Paulo, Botany } \\
\text { French, Kristine; University of Wollongong, School of Earth, Atmospheric } \\
\text { and Life Sciences } \\
\text { Waterman, Melinda; University of Wollongong, School of Earth, } \\
\text { Atmospheric and Life Sciences } \\
\text { Robinson, Sharon; University of Wollongong, School of Earth, } \\
\text { Atmospheric and Life Sciences } \\
\text { Furlan, Claudia; University of Sao Paulo, Botany }\end{array}$ \\
\hline Keywords: & \begin{tabular}{l} 
Abiotic stress, common bean, phenolic compounds, soluble sugars, wax \\
\hline
\end{tabular} \\
\hline
\end{tabular}

\section{SCHOLARONE" Manuscripts}


UV-B and Drought Stress Influenced Growth and Cellular Compounds of Two Cultivars of Phaseolus vulgaris L. (Fabaceae)

Déborah Y. A. C. Santos*1, Marcelo J. Pena Ferreira*1, Tamara Machado Matos ${ }^{1}$ Wilton Ricardo Sala-Carvalho ${ }^{1}$ Fernanda Anselmo-Moreiraㄹ, Lucas Paradizo Roma ${ }^{1}$, Juliana Cajado Souza Carvalhoㄹ, Edgar Miguel Peña-Hidalgo, Kristine French², Melinda J. Waterman², Sharon A. Robinson², Claudia M. Furlan*1

1. Department of Botany, Institute of Biosciences, University of São Paulo, Rua do Matão, 277, 05508-090, São Paulo, SP, Brazil, 2. School of Earth, Atmospheric and Life Sciences, University of Wollongong, Wollongong, NSW 2522, Australia

*Corresponding author e-mail: dyacsandib.usp.br (D.Y.A.C. Santos); marcelopenadib.usp.br (M.J.P. Ferreira); furlancmeib.usp.br (C.M. Furlan). Phone number: $+55-11-3091-8065$. 


\section{ABSTRACT}

20 Combined enhanced UV-B radiation and drought may induce different 21 morphological and physiological alterations in plants than either

22 abiotic stress alone. We evaluated morphology, biomass, primary

23 and secondary metabolism changes in seedlings of two common bean 24 cultivars, IAC Imperador (drought-resistant) and IAC Milênio. To 25 test the hypothesis that cultivars responded differently to 26 combined stresses in a controlled environment, seedlings wte 27 exposed to UV-B and/or drought treatments for three weeks. The 28 cultivars behaved differently, especially to the drought 29 treatment, suggesting that they use different mechanisms to cope 30 with unfavorable environmental conditions. IAC Imperador showed 31 a stronger protective response, modifying wax composition and 32 primary metabolism, and improving its tol $\overline{\bar{r}}$ ance to UV-B 33 radiation. For IAC Imperador, the accumulation of cuticular wax 34 and alkane was higher under combined stress but production of 35 primary alcohols was reduced, suggesting a possible fatty acyl 36 switch. Root/shoot length and biomass ratios increased in both 37 cultivars, particularly for the combined stress, indicating a 38 common plant response. We show that these two bean cultivars 39 responded more strongly to UV-B and combined stress than drought 40 alone as evident in changes to their chemistry and biology. This 
41 shows the importance of investigating plant morphological and 42 physiological responses to combined stress. 
45 Anthropogenic activities, especially those related to the emission of atmospheric pollutants, are causing climate change, such as global warming through increasing atmospheric $\mathrm{CO}_{2}$ levels. Climate change can affect, among other conditions, precipitation cycles, increasing the (2). The release of atmospheric pollutants have increased the quantity of damaging ultravioletB radiation (UV-B; 280-315 nm) reaching Earth's surface due to stratospheric ozone depletion. This ozone depletion, caused by emission of chlorofluorocarbons (CFCs) and other gases, has increased UV-B-induced DNA damage (3), lowered production (4) and has enhanced secondary plant compound levels (4-6).

Plants live in environments subjected to constant transformations and are exposed to biotic and abiotic factors that can interrupt growth and development. While research has focused on understanding single environmental factors on plant growth, plants naturally face exposure to multiple stresses simultaneously. These may be antagonistic or synergistic for different plant processes. Understanding the consequences of multi-stress exposure is important, but not often investigated $(5,6)$. This is particularly relevant as climatic change intensifies environmental stresses (7). Therefore, the development of new cultivars resistant to environmental stress is vital to maintain agricultural production and sustain human populations (8). Resistant cultivars are physiologically capable of coping with, at least, one prevailing stress (9) as a result of metabolic and structural adaptation (10). We investigated whether changes to one environmental stress confers resistance to other stresses.

Combining a water deficit with increased UV-B radiation may cause different effects on plants than either stress alone. Responses will depend on the intrinsic told ce of a species to these 
67 two abiotic factors and the period of exposure to the stresses, potentially leading to either 68 irreversible damage or induced resistance. As both stresses (drought and increased UV-B 69 radiation) can cause growth inhibition in plants, plant responses may be intensified when they

\section{MATERIALS AND METHODS}

To explore physiological and morphological changes in two cultivars of the common bean

(Phaseolus vulgaris L., Fabaceae) in response to enhanced UV-B radiation and drought, we used plants under laboratory conditions. 
89 Plant material: Seeds of two bean cultivars were obtained from the Instituto Agronômico de Campinas (IAC). Seeds of IAC Imperador and IAC Milênio contain approximately 21\% protein and are resistant to two phytopathogenic diseases, anthracnose (Colletotrichum lindemuthianum) and fusariosis (Fusarium oxysporum). IAC Imperador has a quick maturity life cycle of 7075 days and production of $2,266 \mathrm{~kg} \mathrm{ha}^{-1}$ (13), reached with lower rates of irrigation (approximately 30\% less water) than other bean cultivars. IAC Milênio has a life cycle of 90-95 days, and production of $2,831 \mathrm{~kg} \mathrm{ha}^{-1}$ (14). As plants were only grown for three weeks (21 days), differences in the time to maturity of these two cultivars is likely to have a relatively small effect on our results, although it cannot be ruled out completely.

102 Experimental design: Seeds were sown in 40 pots (four seeds/pot) with 103 a mixture of vermiculite:soil (3:1). Germination was carried out 104 in a chamber (FANEM 347-CDG, Brazil) with a 12/12 h light/dark 105 photoperiod at constant $25^{\circ} \mathrm{C}$. The same chamber was used for the 106 experiment with the two UV-B treatments performed first followed 107 by the non UV-B treatments. All other conditions were consistent. 108 For the control (C) and drought (D) groups, the chamber was 109 equipped with four white fluorescent lamps (Osram, Germany; 20 W; 110 range of 100-300 $\mu \mathrm{mol} \mathrm{m}^{-2} \mathrm{~s}^{-1}$ measured with a Li-Cor Biosciences 11 Model Li-250A sensor) and each pot (10 per treatment) received 10 $112 \mathrm{~mL}$ of distilled water every two days. The drought condition (D) 
113 was initiated by suspending the water supply as soon as epigeal

114 germination was observed. For the other treatments, seeds

115 received UV-B supplementation (UVB) for 2 h during the first half

116 of the light period, corresponding to a daily dose of $10.2 \mathrm{~kJ} \mathrm{~m}^{-2}$

117 (measured by MACAM Ultraviolet Radiometer (Scotland) connected to

118 an UV-B specific sensor), by replacing one of the fluorescent

119 lamps by a UV-B lamp (TL 20W/01 RS SLV/25, Philips, Netherlands).

120 For the UVB treatment each pot continued to received $10 \mathrm{~mL}$ of

121 distilled water every two days. For plants exposed to drought

122 and UV-B (UVB+D), watering was suspended as soon as epigeal

123 germination was observed. Pots were randomly rotated daily for

124 all treatments.

125 Plant sampling: After three weeks, the first trifoliate leaf was

126 harvested from all plants (ten plants per treatment) and analyzed

127 for biomass, waxes, primary and phenolic metabolites. This

128 ensured that all leaves were of the same developmental age. One

129 leaflet was separated and dried at $45^{\circ} \mathrm{C}$; the other two leaflets

130 were frozen in nitrogen and kept at $-80^{\circ} \mathrm{C}$ until analysis.

131 Leaflets from two randomly chosen individuals of the same

132 treatment were combined to achieve an appropriate mass for

133 chemical analyses $(\mathrm{n}=5)$.

134 Biomass analysis: After sampling of the first trifoliate leaf, plants

135 were harvested and roots washed to remove soil particles then

136 excess water removed using blotting paper. Root and shoot lengths 
137 were measured, separated, dried at $45^{\circ} \mathrm{C}$ for five days, and the

138 dry weight determined. Root/shoot biomass and length ratios were

139 calculated.

140 Cuticular wax analysis: Dried leaflets were first measured to

141 obtain the surface area using the software Image J 1.49. After

142 that, they were washed twice in dichloromethane $\left(\mathrm{CH}_{2} \mathrm{Cl}_{2}\right)$ for 20

$143 \mathrm{~S}$ at room temperature $\left(\sim 25^{\circ} \mathrm{C}\right)$ to extract cuticular waxes

144 (modified from 15). The extracts were filtered and dried in a

145 rotary evaporator under vacuum at $40^{\circ} \mathrm{C}$. The wax was further

146 dried to a constant mass in a desiccator. The total wax content

147 was calculated as $\mu \mathrm{g} \mathrm{cm}^{-2}$.

148 Cuticular waxes were derivatized using pyridine (50 $\mu \mathrm{L}$, CAS

149 110-86-1, Synth) and N,O-bis-(trimethylsilyl)-

150 trifluoroacetamide (50 $\mu \mathrm{L}$, BSTFA, CAS 25561-30-2, Sigma-Aldrich

151 ) for 1 h at $70^{\circ} \mathrm{C}$ (modified from 16), and analyzed by gas

152 chromatography (6850 Network GC System - Agilent) coupled to

153 mass spectrometry (Agilent 5975C VL MSD) (GC-MS) equipped with

154 a HP5-MS capillary column (Agilent, length $30 \mathrm{~m}$, ID $250 \mu \mathrm{m}$,

$1550.25 \mu \mathrm{m}$ film thickness). The initial column temperature was

156 adjusted to $100^{\circ} \mathrm{C}$ for $5 \mathrm{~min}$, and ramped at $5^{\circ} \mathrm{C} \mathrm{min}-1$ to a final

157 temperature of $320^{\circ} \mathrm{C}$, with a total run time of $49 \mathrm{~min}$. The

158 injection volume was $1 \mu \mathrm{L}$ with helium as a carrier gas at $1 \mathrm{~mL}$

$159 \mathrm{~min}^{-1}$. The injector, ion source, and quadrupole temperatures

160 were $300^{\circ} \mathrm{C}, 230^{\circ} \mathrm{C}$, and $150^{\circ} \mathrm{C}$, respectively. MS detection was 
161 performed with electron ionization (EI) at $70 \mathrm{eV}$, working in 162 the full-scan acquisition mode ranging between $50-600 \mathrm{~m} / \mathrm{z}$ at $1632.66 \operatorname{scan~s}^{-1}$.

164 Wax compounds were identified by comparison of mass

165 fragmentation using NIST digital library spectra (v2.0, 2008)

166 and fragmentation pattern. Peaks with relative percentages

167 lower than 1\% in the chromatogram were not considered for the 168 analysis.

169 Primary metabolites analysis: Analysis of primary metabolites 170 was made according to Lisec et al. (17), with modifications.

171 Frozen leaflets (50 mg) were extracted with $700 \mathrm{\mu L}$ of pre-

172 cooled methanol $\left(-20^{\circ} \mathrm{C}\right)$ and briefly stirred. Afterwards, $60 \mu \mathrm{L}$

173 of ribitol (0.2 $\mathrm{mg} \mathrm{mL}^{-1}$, used as an internal standard) was added

174 and incubated for $10 \mathrm{~min}$ at $70^{\circ} \mathrm{C}$ and $950 \mathrm{rpm}(142 \mathrm{~g})$. The

175 mixture was centrifuged (10 min at 11,000 g), before the

176 supernatant was transferred to glass tubes, and chloroform (375

$177 \mu \mathrm{L}$ at $\left.-20^{\circ} \mathrm{C}\right)$ and distilled water $\left(750 \mu \mathrm{L}\right.$ at $\left.4^{\circ} \mathrm{C}\right)$ added. After

178 stirring, the mixture was centrifuged for $15 \mathrm{~min}$ at 2,200 $\mathrm{g}$ and

179 the polar phase was collected.

180 The polar phase was derivatized using methoxyamine

181 hydrochloride (28 $\mu \mathrm{L}$, CAS 593-56-6, Sigma-Aldrich) for $2 \mathrm{~h}$ at $18237^{\circ} \mathrm{C}$ and $\mathrm{N}$-Methyl-N-(trimethylsilyl) trifluoroacetamide (48 $\mu \mathrm{L}$, 183 MSTFA, CAS 24589-78-4, Sigma-Aldrich) for $30 \mathrm{~min}$ at $37^{\circ} \mathrm{C}$. 184 Primary metabolites were analyzed by GC-MS (as above) equipped 
185 with the VF-5ms column (Agilent, length $30 \mathrm{~m}$, ID $250 \mu \mathrm{m}, 0.25$

$186 \mu \mathrm{m}$ film thickness) and a pre-column $(0.25 \mathrm{~mm} \times 10 \mathrm{~m})$. The

187 initial column temperature was adjusted to $70^{\circ} \mathrm{C}$ for $5 \mathrm{~min}$, and

188 ramped at $5^{\circ} \mathrm{C} \mathrm{min}-1$ to a final temperature of $295^{\circ} \mathrm{C}$, with a

189 total run time of $50 \mathrm{~min}$. The injection volume was 1 uL with

190 helium as a carrier gas at $1 \mathrm{~mL} \mathrm{~min}^{-1}$. The injector, ion source,

191 and quadrupole temperatures were $230^{\circ} \mathrm{C}, 200^{\circ} \mathrm{C}$, and $150^{\circ} \mathrm{C}$,

192 respectively. MS detection was performed with electron

193 ionization (EI) at $70 \mathrm{eV}$, working in the full-scan acquisition

194 mode ranging between $50-600 \mathrm{~m} / \mathrm{z}$ at $2.66 \mathrm{scan} \mathrm{s}^{-1}$.

195 Compound identification was made by comparison of mass

196 fragmentation using NIST digital library spectra (v2.0, 2008)

197 and through Linear Retention Index (LRI). An alkane mixture

198 ranging from $\mathrm{C}_{8}$ to $\mathrm{C}_{28}$ was injected every ten samples. The

199 alkane mixture consisted of a standard solution of alkanes $\mathrm{C}_{8}{ }^{-}$

$200 \mathrm{C}_{20}$ (Sigma-Aldrich) with addition of alkane standards $\mathrm{C}_{21}-\mathrm{C}_{28}$

201 (PolyScience), except for the $\mathrm{C}_{27}$ homologue. The Linear

202 Retention Index (LRI) was calculated for each compound using

203 the alkane standard mixture according to Viegas and Bassoli (18)

204 and compared with the Golm Metabolome Database (GMD)

205 (http://gmd.mpimp-golm.mpg.de/), European Mass Bank database

206 (https://massbank.eu/MassBank/Index), and literature (19).

207 Phenolic compounds analysis: Frozen leaflets were extracted

208 with acetone:water (8:2) in an ultrasonic bath for $30 \mathrm{~min}$. The 
samples were centrifuged at $14,000 \mathrm{rpm}(20,817 \mathrm{~g})$ for $3 \mathrm{~min}$ and

210 the supernatant transferred to a fresh tube. The extraction

21 procedure was repeated until exhaustion. Extracts were pooled

212 and concentrated under vacuum (SpeedVac concentrator,

213 Vacufugue ${ }^{\circ}$ plus) to reduce the proportion of organic solvent

214 and water was removed through freeze-drying (Liofilizador K202,

215 Liotop). Samples were dissolved in water to solubilize polar

216 compounds. The aqueous fraction was collected and subsequently

217 freeze-dried (20).

218 Dried aqueous fractions were then weighed, diluted in water to

219 achieve a concentration of $5 \mathrm{mg} \mathrm{mL}^{-1}$, and analyzed by High-

220 Performance Liquid Chromatography coupled to a diode array

221 detector (HPLC-DAD 1260 - Agilent) through a C18 column (Zorbax

222 Eclipse Plus, $4.6 \times 150 \mathrm{~mm}, 3.5 \mathrm{\mu m}$ ) at $45^{\circ} \mathrm{C}$. The mobile phase

223 had a constant flow of $1 \mathrm{~mL} \mathrm{~min}^{-1}$ and a gradient elution of $0.1 \%$

224 acetic acid (A) and acetonitrile (B), starting with 100\% (A),

225 decreasing to 85\% (A) for the next $6 \mathrm{~min}$, then to $70 \%$ (A) for

22620 mins, decreasing to $0 \%$ (A) for the next $1 \mathrm{~min}$ and finishing

227 with an isocratic phase for the last $4 \mathrm{~min}$. Absorbance

228 detection was performed at $\lambda=280$ and $352 \mathrm{~nm}$. A post-run of 5

229 min was applied to return to initial conditions.

230 Compounds detected at 280 and 352 nm were classified as non-

231 flavonoid phenolics and flavonoids respectively, according to

232 their UV absorption spectra. Non-flavonoid compounds were 
233

234

235

236

237

238

239

240

241

242

243

expressed as mg of gallic acid equivalents (GAE) per g of fresh weight (FW), while flavonoids were expressed as mg of rutin equivalents (RE) $\mathrm{g}^{-1}$ fresh weight (FW). Total phenolics were obtained from the sum of flavonoid and non-flavonoid fractions and are expressed $\mathrm{mg}^{-1} \mathrm{FW}$. Only peaks with an abundance above 20 mAU were considered.

Statistical analysis: Two factor permutational multivariate analyses of variance (PERMANOVAs) were used to identify changes in biomass variables and composition of cuticular waxes, primary metabolites and phenolic compounds amongst the two cultivars and the stress treatments (PRIMER v7, PRIMER-E Ltd). For waxes and primary metabolites, Bray Curtis dissimilarity indices were used to measure differences amongst samples. For the biomass variables and phenolic compounds, data were first normalized as each compound was measured on a different scale, then Euclidean distances were calculated. Pairwise comparisons were performed within the PERMANOVA module to identify where differences lay. Data were visualized in non-metric multidimensional scaling ordinations (nMDS) for bootstrapped group averages with 95\% confidence intervals (no. bootstraps per group $=38$ ).

Individual compounds were then compared using univariate statistics by Kruskal-Wallis rank test followed by a post-hoc Dunn test, using R software (version 3.5.3). Heatmaps were made using the Morpheus platform (https://software.broadinstitute.org/morpheus/).

To elucidate differences between control and treatments, heatmap analysis were performed by transforming obtained data, using the formula below. As a result, data in heatmaps are presented as values normalized to their respective control.

$$
\mathrm{TD}=\mathrm{C}-\log _{2}\left(\mathrm{~T}^{*} 1000\right)
$$

TD: Transformed data, C: Control data, T: Treatment data 


\section{RESULTS}

\section{Growth and biomass production}

Differences in biomass allocation patterns were evident amongst

$$
\text { P. vulgaris L. cultivars (Pseudo } \mathrm{F}_{1,67}=4.971, \mathrm{p}=0.004 \text { ) and }
$$

within treatments (Pseudo $\mathrm{F}_{3,67}=15.467, \mathrm{p}=0.001$ ). The

pattern of change in biomass allocation within treatment was

the same for each cultivar (interaction term NS: Pseudo $F_{3,67}=$ 0.920, $\mathrm{p}=0.502)$. Pairwise comparisons identified differences amongst all pairs of treatments, which are well depicted in the ordination (Fig. 1) .

In general, when compared to control, treatments affected the growth and biomass production of both cultivars (see Supplementary Materials). Seedlings were significantly shorter when exposed to UV-B radiation in comparison to the control (Fig. 2a). For IAC Imperador, seedling shoot length was $29.7 \%$ and $28.1 \%$ shorter for combined stress (UVB+D) and UVB, respectively. Shoots of IAC Milenio 274 seedlings were $38.9 \%(U V B+D)$ and $34.5 \%$ (UVB) of the length of

275 the control. Although neither drought nor UV-B appeared to affect root length

276 separately, roots were significantly longer under the combined stress than the UVB treatment 277 alone for the IAC Imperador cultivar (Fig. 2b). Consequently, it is unsurprising that shoot 278 length strongly influences the root/shoot length ratio resulting in a significant increase in both 
279 UVB treatments for IAC Milênio and only UVB+D for IAC Imperador compared to the 280 control (Fig. 2c).

$281<$ Figure 2>

282 In contrast with shoot length, no significant difference in shoot dry biomass was

283 observed between the treatments for either cultivar (Fig. 2d). However, except for drought

284 treatment of IAC Imperador, root dry biomass of both cultivars increased when submitted to

285 stressful conditions (Fig. 2e). This increase subsequently increased root/shoot dry mass,

286 especially for UVB treatments, resulting in the UVB+D treatment being significantly higher

287 than the control for both cultivars and UVB alone also being higher in IAC Milênio (Fig. 2f).

Cuticular waxes

289 The effect of treatment on the composition of waxes varied

290 between bean cultivars (Pseudo $\mathrm{F}_{3,30}=9.886, \mathrm{p}=0.001$ ) (Fig.

291 3a). The two cultivars did not differ in cuticular wax content

292 for controls ( $\mathrm{p}=0.111)$, but differed for all other treatments

$293(\mathrm{p}<0.025)$ (see Supplementary Materials). Total wax content was similar

294 for both $P$. vulgaris cultivars under control conditions with $40.74 \pm 34.87 \mu \mathrm{g} \mathrm{cm}^{-2}$ for IAC

295 Imperador and $31.92 \pm 7.52 \mu \mathrm{g} \mathrm{cm}^{-2}$ for IAC Milênio (Fig. 4a and see Supplementary

296 Materials). IAC Milênio tended to have more primary alcohols

297 ( $\mathrm{PA} \mathrm{C}_{26}$ and $\mathrm{PA} \mathrm{C}_{28}$ ), while IAC Imperador tended to have more

298 alkane $\mathrm{C}_{31}$ (Table 1, Fig. 4b).

$299 \quad<$ Figure 3>

300

$<$ Figure $4>$ 
Wax compound classes found in P. vulgaris were alkanes, primary alcohols, fatty acids and steroids (Table 1, Fig. 4b). Primary alcohols and alkanes were the most abundant classes, comprising between $89-95 \%$ of compounds. Fatty acids and steroids were detected only under enhanced UV-B (UVB and UVB+D) for both cultivars (Table 1). For IAC Imperador, while alkanes increased across stress treatments (D, UVB, UVB+D), primary alcohols decreased in abundance (Table 1). For IAC Milênio, no difference was found for any treatment.

A total of 18 wax compounds were identified: 10 alkanes $\left(\mathrm{C}_{24}-\mathrm{C}_{33}\right)$, five primary alcohols $\left(\mathrm{C}_{24}-\mathrm{C}_{32}\right)$, one fatty acid (hexadecanoic acid), and two steroids (stigmasterol and $\beta$ sitosterol) (Table 1). Among the alkanes, nonacosane $\left(\mathrm{C}_{29}\right)$ and hentriacontane $\left(\mathrm{C}_{31}\right)$ were the dominant compounds in both cultivars. For IAC Imperador, shorter chain alkanes $\left(\mathrm{C}_{24}\right.$ to $\left.\mathrm{C}_{26}\right)$ appeared only under UVB treatment. For both cultivars, the primary alcohols were distributed in an even homologous series with hexacosanol $\left(\mathrm{C}_{26}\right)$ and octacosanol $\left(\mathrm{C}_{28}\right)$ as major homologues.

\section{Primary metabolites}

Twenty-three primary metabolites were detected, comprising soluble sugars, amino acids, and carboxylic acids (Table 2). Overall, there were differences in primary metabolite composition between all treatments (Pseudo $\left.\mathrm{F}_{3,30}=3.786, \mathrm{p}=0.001\right)$ and between the two cultivars (Pseudo $\left.\mathrm{F}_{1,30}=3.716, \mathrm{p}=0.002\right)($ see Supplementary Materials). Pairwise tests identified all treatments differed from all others in composition, except the control and drought treatments (Fig. 3b).

$$
<\text { Table 2> }
$$


For IAC Milênio, there was no significant difference in total soluble sugars, amino

acids or total carboxylic acid contents (Fig. 5) (see Supplementary Materials). IAC

325 Imperador also showed no significant difference in total soluble sugars (Fig. 5a). However, for

326 IAC Imperador the total amino acid and carboxylic acid contents were significantly higher for $\mathrm{UVB}+\mathrm{D}$ treatment when compared to UVB alone (Fig. 5b, 5c). In addition, amino acid content was also lower in the UVB treatment when compared to the drought treated plants (Fig. 5b).

Concentrations of fructose and glucose were similar in all treatments for both cultivars (Tables 3 and 4). For IAC Milênio significantly higher levels of sucrose (3-fold) were found in the $\mathrm{UVB}+\mathrm{D}$ treatment than in the control (Table 4). On the other hand, for IAC Imperador, ribonic acid was found only in treatments submitted to drought stress (D and UVB+D) (Table 3).

$<$ Table 4>

For amino acids, aspartic acid was found in all UV-B irradiated plants of both cultivars (Tables 3 and 4), with the exception of the UVB treated IAC Imperador (Table 3). Moreover, drought and UVB+D treated IAC Imperador showed higher glutamic acid content than UVB alone; and drought treatment in this cultivar also presented a higher content of 5-oxoproline when compared with UVB (Table 3). For IAC Imperador and IAC Milênio, GABA was found in both treatments with UV-B irradiation (UVB and UVB+D), but not in control or drought only treatments (Tables 3 and 4).

In the IAC Imperador cultivar, tartaric acid was present in all treatments, except the UVB treatment. In addition, $U V B+D$ showed a higher content of malic acid than UVB and D 
346 applied singly (Table 3). Succinic acid was detected in both cultivars; however, in IAC 347 Imperador, it was not detected in the UVB treatment (Tables 3 and 4).

\section{Phenolic compounds}

Two distinct groups of phenolic compounds were identified: 1) non-flavonoid phenolics represented by maximum absorption between 220 and $326 \mathrm{~nm}$, and 2) flavonoids detected by the presence of two peaks typical for flavonoids, one at 240-266 nm and another at 328-360 nm. However, no difference (see Supplementary Materials) in overall phenolic composition was found between cultivars or treatments (Fig. 3C).

\section{DISCUSSION}

We evaluated the morphological and biochemical responses of two cultivars of the common bean, Phaseolus vulgaris, to elevated UV-B radiation and drought conditions. The combined UV-B and drought treatment on both cultivars was greater than the individual stressors, especially for biomass allocation and wax

360 composition. We showed that the two cultivars, IAC Imperador and Milênio, differed in their response to drought and UV-B,

362 showing changes to plant growth, biomass, composition of

363 cuticular waxes and primary metabolites. As predicted, IAC

364 Imperador was able to withstand the drought treatment with a

365 lower impact on plant shoot and root growth compared to IAC 
contrast, cuticular wax composition did not change in IAC

Milênio in response to either drought or UVB treatments.

Growth and biomass production

370

371

372

373

374

375

376

Both cultivars showed similar patterns of response to stresses with more pronounced changes in growth in response to combined stress (UVB+D), than either stress treatment separately (D or UVB). However, these responses were not additive, resulting in a more subdued increase. These results differ from published studies and show that responses to combined stresses can be species specific. Additive effects of UV-B radiation and drought have been observed for willows (21), whereas for pea, wheat, maize, and soybean, growth was lower, but not additive, in response to combined stress $(22,23)$. This suggests the presence of some mechanism that mitigates the adverse effects caused by the combined stress conditions in these crop plants. Water is a limiting factor at the initial phase of plant growth, affecting elongation and expansion (24), and roots commonly become more pronounced and deeper due to an increase of assimilate supply for this organ, to foster more efficient use of soil water (25-27). Sartori et al. (28) described reductions in photosynthetic capacity and carbon assimilation in plants of IAC Imperador with only two days of water restriction. In our study, shoot biomass did not change in either cultivar under any treatment and changes under stress were largely associated with increasing allocation to root biomass. For both cultivars, root biomass increased with the combined stresses, also evident in increases in length and biomass shoot/root ratios. At these young stages, roots represented about $16 \%$ of the total biomass allocation in controls, increasing to about $20 \%$ with combined stress. Omae et al. (29) observed shoot reduction in different bean cultivars submitted to water stress and correlated this feature with the water retention capacity in drought situations. We did not see this in our seedlings. 
390 In both cultivars, the effect of UVB on biomass seemed more pronounced than the effect of 391 drought, with shorter shoots observed under UVB than drought treatment, although this was 392 not significant. This allocation of more biomass to roots in plants growing under enhanced

393 UV-B radiation has been reported elsewhere (30). While the same general response pattern to treatment was verified for both cultivars in growth and biomass parameters, IAC Milênio responded more to drought stress alone than IAC Imperador in respect of changes to root growth under drought (Fig. 2e-f), suggesting that IAC Milênio invests more in morphological changes for acclimation to drought.

\section{Cuticular waxes}

High levels of UV-B radiation (31-33) and water deficit (34-39) can increase the amounts of total waxes. However, differences among control and treatments were not detected for either cultivar of $P$. vulgaris in our study, suggesting that high levels of cuticular protection may already be present in these plants and are not induced by higher exposure to either stress. Similar patterns of wax content across treatments in response to UV-B irradiation were also observed in Brassica napus L. leaves (39) and fruits (40), and in needles of different species of pine (Picea spp.) (41). The absence of increased wax amounts under UV-B irradiation does not indicate a lack of UV-B protection. Despite the reported correlation of increased wax content in the presence of UV-B light, the varied optical properties of cuticular wax crystals are also an important factor in controlling reflection of excess incoming radiation $(35,42,43)$, probably being more so than cuticle thickness alone.

Large changes were found in cuticular wax composition across treatments (Fig. 3a). IAC Milênio had a minor response to stresses, while IAC Imperador responded more strongly (Fig. 4b). IAC Imperador produced more alkanes, suggesting an investment to protect the plant 
413 against environment changes; IAC Imperador may increase its drought-resistance through

414 accumulating compounds, such as alkanes, with higher hydrophobicity to protect the cells

415 against stresses.

416 There are several indications suggesting that wax composition is a very important attribute

417 related to water retention in the cuticle. Alkanes are the most hydrophobic wax constituents,

418 being more efficient for plant water retention than alcohols and ketones (44). IAC Imperador

419 did not show increases in wax content, but exhibited an enhanced proportion of alkanes,

420 mainly $\mathrm{C}_{29}$ and $\mathrm{C}_{31}$, together with a reduction of primary alcohols, across treatments,

421 particularly under combined stress (UVB+D). This might improve water retention particularly

422 when drought was associated with enhanced UV-B radiation. In contrast, IAC Milênio showed

423 no change in alkane proportions. Apparently, in IAC Milênio, changes in cuticular waxes as a

424 protective mechanism against drought and UVB stress are not triggered.

425 The presence of hexadecanoic acid and steroids ( $\beta$-sitosterol and stigmasterol) in the waxes of

426 both cultivars seem to be UV-B dependent. This is the first time that a possible correlation

427 between the presence of fatty acids and steroids associated with enhanced UV-B irradiation

428 has been reported. Further studies are necessary to confirm this idea and verify if these

429 compounds improve protection for plants.

\section{Primary metabolites}

431 Primary metabolites such as lipids, proteins, sugars and amino acids are essential for many

432 plant physiological processes, such as photosynthesis, protein synthesis and nutrient

433 absorption (45). Changes in environmental conditions can impact primary metabolite

434 production (46). It is known that drought treatment can alter primary metabolites, increasing

435 carbohydrates levels, such as sucrose (46). The two bean cultivars had different primary 
436 metabolite content (Fig. 3b) associated with a higher production of sucrose in IAC Imperador

437 in all treatments, except UVB+D which showed similar concentrations for both cultivars.

438 Resistance in IAC Imperador may be mediated through a significant change in cellular

439 metabolites.

440 Increases in non-structural carbohydrate concentrations in plants growing under high doses of

441 UV-B light is suggested to be due to mitochondrial damage, resulting in a decrease of

442 respiratory utilization of substrate, favoring the accumulation of sugars (47). Pea plants (Pisum

443 sativum), submitted to high doses of UV-B (12.9 $\mathrm{kJ} \mathrm{m}^{-2}$ day $\left.^{-1}\right)$ were characterized by an $89 \%$

444 increase of total soluble sugars in comparison to those under ambient UV-B (48). Such a

445 response was not apparent in the cultivars used in this study, which did not show changes in

446 total soluble sugars content when submitted to a higher dose of UV-B radiation alone. These

447 cultivars may have similar protective mechanisms against UV-B radiation and water stress.

448 Often under water stress, the content of total soluble sugar can increase or decrease depending

449 on the level of stress to which a particular plant is exposed, decreasing carbon assimilation and

450 consequently growth. Soluble sugars have a similar function as amino acids, protecting

451 membranes against dehydration by reducing the osmotic potential and regulating water

452 transport. Water stress affects the total soluble sugar content differently in a range of legumes

453 according to genotype. For Cajanus cajan (L.) Millsp., for instance, the accumulation of total

454 soluble sugars was not influenced by water stress levels, whereas changes were apparent for

455 other species (49). Although some of these sugars were detected in both cultivars, there was

456 also no significant difference overall in these compounds in any treatments relative to the

457 control (Fig. 5a). 
458 Both drought and UV-B irradiation may have contributed to the higher content of amino acids

459 in IAC Imperador under the combined stress. Increased total amino acids can occur under

460 drought stress and is responsible for osmotic adjustment, avoiding tissue dehydration or even

461 protecting subcellular structures against the deleterious effects of drought (49-51). The total

462 amino acids increased in IAC Imperador submitted to combined stress when compared to

463 UVB radiation alone, ind $\overline{=}$ the importance of drought stress to amino acid accumulation.

464 GABA (gamma-aminobutyric acid) is a well-known intermediate for amino acid metabolism

465 and, in plants, it is accumulated in response to a wide range of environmental stresses. Thus,

466 GABA can act as a signal to maintain cellular metabolism or, under water stress, can act as a

467 potential osmolyte assisting in the absorption of water. In other cultivars of common beans

468 under combined stresses, GABA also acts as a significant antioxidant, helping ameliorate the

469 deleterious effects of these stresses (52). In both $P$. vulgaris cultivars in our study, GABA was

470 detected only in plants subjected to UV-B irradiation, suggesting that it might also act as an

471 antioxidant compound here.

\section{Phenolic compounds}

473 UV-B radiation incidence and drought were expected to cause changes in phenolic compound 474 production (11) as drought triggers accumulation of $\mathrm{H}_{2} \mathrm{O}_{2}$ and lipid peroxidation, which leads 475 to an overexpression of genes that regulate flavonoid production (53). However no difference control and UVB treatments. Flavonoid biosynthesis is correlated with the incidence of UV-B,

479 UV-A and visible light (54). Experiments carried out in growth chambers, as in this study, lack 480 UV-A radiation and have low visible light compared to sunlight, which may weaken the ability 
481 of a plant to respond appropriately to UV radiation (55). However, our other results show that 482 the plants were able to enhance other UV photoprotection, so low flavonoid content may be 483 the normal response. Field trials under natural, filtered and/or supplemental UV conditions 484 would resolve this. Heatmap and biosynthetic pathways shifts

Differences between treatments are highlighted in the heatmap with identified connections to the biosynthetic pathways (Fig. 6). The greater production of sucrose in both cultivars submitted to stressful conditions may be detrimental for IAC Imperador as it was coupled with declines of sucrose monomers, fructose and glucose. These precursor compounds appear to be depleted in IAC Imperador under drought conditions when ribonic and tartaric acid synthesis is enhanced, while the synthesis of myo-inositol seems to decrease. On the other hand, IAC Milênio, despite also showing a greater amount of sucrose and ribonic acid in UVB treatments, seems to accumulate both fructose and glucose. We can verify that IAC Milênio produces myo-inositol when submitted to stressful conditions, while IAC Imperador does not increase 495 production of this compound.

$496<$ Figure 6>

It is likely that part of both fructose and glucose production was directed to the glycolysis pathway to form glyceraldehyde 3-P, pyruvic acid and acetyl-CoA. Acetyl-CoA is either shifted to the citric acid cycle, malonate or to mevalonate pathways. It seems that acetyl-CoA was used as a by-product of mevalonate to synthesize steroids to be deposited as wax constituents; this pattern was seen in both cultivars when submitted to UV-B radiation. In IAC

502 Milênio, other products of the glycolysis pathway, such as phosphoenolpyruvate perhaps, 
504 pathway to produce phenolic compounds when submitted to the stressful conditions. This kind

505 of pattern was not seen in IAC Imperador which either slightly reduced or maintained the same

506 quantity of phenolics.

507 In the malonate pathway some acetyl-CoA might be used to produce hexadecanoic acid in

508 plants treated with UV-B radiation, e.g. in the case of IAC Imperador, or submitted to UV-B

509 and UVB+D treatments as in IAC Milênio. While fatty acyl groups are the initial substrates in

510 wax synthesis for either primary alcohols or alkanes (56), evidently, under the stressful

511 UVB+D condition, the IAC Imperador cultivar switched the use of these fatty acyls from the

512 acyl reduction pathway to the decarboxylation pathway. This shift was not observed in IAC

513 Milênio which maintained the same proportion of both waxy compounds.

514 IAC Milênio may shift acetyl-CoA to the citric acid cycle instead of the malonate pathway,

515 producing more carboxylic acids and amino acids, such as citric acid, succinic acid, aspartic

516 acid, glutamic acid and GABA, when submitted to UV-B radiation, instead of investing in

517 waxy alkanes and primary alcohols. Probably, in IAC Imperador, some acetyl-CoA was used

518 as a product of the citric acid cycle to produce GABA in the UV-B light treatments, reducing

519 the synthesis of other compounds of this cycle, such as malic, citric, succinic, and glutamic

520 acids.

521 Apparently, IAC Milênio invests in phenolic compounds as well as carboxylic and amino acid

522 synthesis as its main chemical defense against those stresses. Conversely, IAC Imperador, the

523 cultivar with water-deficiency resistance, invests in synthesis of waxy constituents mainly

524 under combined stresses, which reinforces the resilience of this cultivar.

\section{CONCLUSION}


526 In general, both cultivars showed more pronounced alterations under combined UV-B and

527 drought (UVB+D) stress, than under UV-B and drought separately. Biomass and growth

528 responses to drought alone were greater for IAC Milênio, which seemed to reallocate resources

529 from shoots to roots possibly in order to optimize water absorption.

530 Under UVB+D the IAC Imperador cultivar invested resources in alkane synthesis at the

531 expense of primary alcohols. This cultivar also invested in the synthesis of ribonic acid, a

532 soluble sugar that can function to reduce osmotic potential under drought treatments. Both

533 cultivars also invested in the production of GABA, a compound that is known for its

534 antioxidant activity, in both UVB and UVB+D treatments. Neither cultivar showed an increase

535 of phenolic compounds in seedlings irradiated with UV-B light.

536 Both cultivars showed a range of other characteristics to combat multiple stresses, increasing

537 the synthesis of waxes and primary compounds and investing more in the root system. These

538 changes were unidirectional for both cultivars, albeit with IAC Imperador having a greater

539 degree of change in the composition of protective compounds against drought, such as alkanes

540 and sucrose. This suggests that improved resistance of IAC Imperador to drought conditions is

541 mediated through significant changes in its cellular metabolites. In contrast, IAC Milênio had

542 greater degrees of change in its growth and biomass parameters, showing that both cultivars

543 use different mechanisms to cope with unfavorable conditions.

544 In summary, both cultivars seem to acclimate to applied stresses. IAC Milênio has a more

545 plastic body development response to the treatments than IAC Imperador, which appeared to

546 have more constitutive resistance, with more pronounced changes in metabolite synthesis.

547 Further studies are necessary to infer which physiological mechanisms and genetic expression

548 are involved and if these can help to improve resilience in other crops. 
549 ACKNOWLEDGMENTS : Authors would like to thank Ailton Nogueira França and Erismaldo

550 Carlos de Oliveira for their technical assistance during assembly of the experiment; Mourisa

551 Ferreira and Aline Bertinatto Cruz for their technical assistance during analysis; Ph.D Alice

552 Nagai for assistance in data analysis; the Instituto Agronômico de Campinas for the donation of 553 seeds used in this study; UGPN (University Global Partnership Network) for grant funding to

554 establish this partnership between Universities of São Paulo and Wollongong. The authors also

555 thank the Brazilian Council for Superior Education (CNPq - process numbers: 164152/2015-6;

$556140120 / 2018-1 ; 145622 / 2018-5 ; 140085 / 2019-0)$. This study was financed in part by the

557 Coordenação de Aperfeiçoamento de Pessoal de Nível Superior - Brasil (CAPES) - Finance 558 Code 001.

559 SUPPLEMENTARY MATERIALS

560 Table S1 and Table S2 can be found at DOI: 10.1562/2006$561 \quad \mathrm{xxXXXX.S1}$

\section{REFERENCES}

563 1. IPCC (2014) Climate Change 2014: Synthesis Report. Contribution of Working Groups I, II

564 and III to Fifth Assessment Report of the Intergovernmental Panel on Climate Change.

565 2. Wheeler, T. and Braun, J. von (2013) Climate Change Impacts on Global Food Security.

566 Science. 341, 508-513. 
3. Turnbull, J. D. and Robinson, S. A. (2009) Accumulation of DNA damage in Antarctic mosses: correlations with ultraviolet-B radiation, temperature and turf water content vary among species. Global Change Biology 15, 319-329.

4. Bernhard, G. H., Neale, R. E., Barnes, P. W., Neale, P. J., Zepp, R. G., Wilson, S. R., Andrady, A. L., Bais, A. F., McKenzie, R. L., Aucamp, P. J., Young, P. J., Liley, J. B., Lucas, R. M., Yazar, S., Rhodes, L. E., Byrne, S. N., Hollestein, L. M., Olsen, C. M., Young, A. R., Robson, T. M., Bornman, J. F., Jansen, M. A. K., Robinson, S. A., Ballaré, C. L., Williamson, C. E., Rose, K. C., Banaszak, A. T., Häder, D.-P., Hylander, S., Wängberg, S.-A., Austin, A. T., Hou, W.-C., Paul, N. D., Madronich, S., Sulzberger, B., Solomon, K. R., Li, H., Schikowski, T., Longstreth, J., Pandey, K. K., Heikkilä, A. M. and White, C. C. (2020) Environmental effects of stratospheric ozone depletion, UV radiation and interactions with climate change: UNEP Environmental Effects Assessment Panel, update 2019. Photochem. Photobio. Sci. in press. https://doi.org/10.1039/d0pp90011g 5. Bornman, J. F., Barnes, P. W., Robinson, S. A., Ballaré, C. L., Flint, S. D. and Caldwell, M. M. (2015) Solar ultraviolet radiation and ozone depletion-driven climate change: effects on terrestrial ecosystems. Photochem. Photobiol. Sci. 14, 88-107. https://doi.org/10.1039/c4pp90034k.

6. Bornman, J. F., Barnes, P. W., Robson, T. M., Robinson, S. A., Jansen, M. A. K., Ballaré, C. L. and Flint, S. D. (2019) Linkages between stratospheric ozone, UV radiation and climate change and their implications for terrestrial ecosystems. Photochem. Photobiol. Sci. 18, 681716. https://doi.org/10.1039/C8PP90061B.

7. Zhu, JK. (2016) Review Abiotic Stress Signaling and Responses in Plants. Cell 167, 313324. https://doi.org/10.1016/j.cell.2016.08.029. 
590 8. Nepomuceno, A. L., Neumaier, N., Farias, J. R. B. and Oya, T. (2001) Tolerância à seca em 591 plantas: mecanismos fisiológicos e moleculares. Biotecnol. Ciência Desenvolv. 23, 12-18.

592 9. Foyer, C. H., Rasool, B., Davey, J. W. and Hancock, R. D. (2016) Cross-tolerance to biotic 593 and abiotic stresses in plants: a focus on resistance to aphid infestation. J. Exp. Bot. 67, 2025594 2037. https://doi.org/10.1093/jxb/erw079.

595 10. Alexieva, V., Ivanov, S., Sergiev, I. and Karanov, E. (2003) Interaction between stresses. 596 Bulg. J. Plant Physiol 29, 1-17.

597 11. Bandurska, H., Niedziela, J. and Chadzinikolau, T. (2013) Separate and combined 598 responses to water deficit and UV-B radiation. Plant Sci. 213, 98-105.

599 https://doi.org/10.1016/j.plantsci.2013.09.003.

600 12. Hofmann, R. W., Campbell, B. D. and Fountain, D. F. (2003) Sensitivity of white clover to 601 UV-B radiation depends on water availability, plant productivity and duration of stress. Glob. 602 Chang. Biol. 9, 473-477. https://doi.org/10.1046/j.1365-2486.2003.00578.x.

603 13. Chiorato, A. F., Carbonell, S. A. M., Carvalho, C. R. L., Barros, V. L. N. P. de, Borges, W. 604 L. B., Ticelli, M., Gallo, P. B., Finoto, E. L. and Santos, N. C. B. (2012) 'IAC IMPERADOR': 605 early maturity "carioca” bean cultivar. Crop Breed. Appl. Biotechnol. 12, 297-300.

606 14. Carbonell, S. A. M., Chiorato, A. F., Bolonhezi, D., Barros, V. L. N. P. de, Borges, W. L.

607 B., Ticelli, M., Gallo, P. B., Finoto, E. L. and Santos, N. C. B. (2014) 'IAC Milênio’ -

608 Common bean cultivar with high grain quality. Crop Breed. Appl. Biotechnol. 14, 273-276.

609 15. Fernandes, A. M. S., Baker, E. A. and Martin, J. T. (1964) Studies on plant cuticle. Ann. 610 Apllied Biol. 53, 43-58.

611 16. Chu, W., Gao, H., Cao, S., Fang, X., Chen, H. and Xiao, S. (2017) Composition and 612 morphology of cuticular wax in blueberry (Vaccinium spp.) fruits. Food Chem. 219, 436-442. 
613 https://doi.org/10.1016/j.foodchem.2016.09.186.

614 17. Lisec, J., Schauer, N., Kopka, J., Willmitzer, L. and Fernie, A. R. (2006) Gas

615 chromatography mass spectrometry - based metabolite profiling in plants. Nat. Protoc. 1, 616 387-396. https://doi.org/10.1038/nprot.2006.59.

617 18. Viegas, M. C. and Bassoli, D. G. (2007) Utilização do índice de retenção linear para 618 caracterização de compostos voláteis em café solúvel utilizando GC-MS e coluna HP-

619 innowax. Quim. Nova 30, 2031-2034. https://doi.org/10.1590/s0100-40422007000800040.

620 19. Nagai, A. (2017) Interação planta-patógeno: análises químicas em Solanum

621 pimpinellifolium L. e Solanum lycopersicum 'VFNT' infectadas pelo tomato mottle mosaic

622 virus. Ph.D. thesis. Universidade de São Paulo.

623 20. Baert, N., Kim, J., Karonen, M. and Salminen, J. P. (2017) Inter-population and inter624 organ distribution of the main polyphenolic compounds of Epilobium angustifolium.

625 Phytochemistry 134, 54-63. https://doi.org/10.1016/j.phytochem.2016.11.003.

626 21. Turtola, S., Rousi, M., Pusenius, J., Yamaji, K., Heiska, S., Tirkkonen, V., Meier, B. and

627 Julkunen-Tiitto, R. (2006) Genotypic variation in drought response of willows grown under 628 ambient and enhanced UV-B radiation. Environ. Exp. Bot. 56, 80-86.

629 https://doi.org/10.1016/j.envexpbot.2005.01.007.

630 22. Alexieva, V., Sergiev, I., Mapelli, S. and Karanov, E. (2001) The effect of drought and 631 ultraviolet radiation on growth and stress markers in pea and wheat. Plant, Cell Environ. 24, 632 1337-1344. https://doi.org/10.1046/j.1365-3040.2001.00778.x.

633 23. Shen, X., Dong, Z. and Chen, Y. (2015) Drought and UV-B radiation effect on

634 photosynthesis and antioxidant parameters in soybean and maize. Acta Physiol. Plant. 37.

635 https://doi.org/10.1007/s11738-015-1778-y. 
636 24. Ahmadizadeh, M. (2013) Physiological and Agro-Morphological Response to Drought

637 Stress. Middle-East J. Sci. Res. 13, 998-1009.

638 https://doi.org/10.5829/idosi.mejsr.2013.13.8.3531.

639 25. Morgan, J. M. (1984) Osmoregulation and water stress in higher plants. Ann. Rev. Plant

$640 \quad$ Physiol. 35, 299-319.

641 26. Shao, H. B., Chu, L. Y., Jaleel, C. A. and Zhao, C. X. (2008) Water-deficit stress-induced 642 anatomical changes in higher plants. Comptes Rendus - Biol. 331, 215-225.

643 https://doi.org/10.1016/j.crvi.2008.01.002.

644 27. Vadez, V. (2014) Root hydraulics: the forgotten side of roots in drought adaptation. $F$.

645 Crop. Res. 165, 15-24. https://doi.org/10.1016/j.fcr.2014.03.017.

646 28. Sartori, F. F., Ferreira, A. C., Hertz, C. E. N., Okamura, E. T., Felisberto, G., Pessoto, M.

647 V., Soave, J. M., Barros, L. P., Almeida, A. A. P., Souza, K. M., Tezotto, T., Brendler, F. O.,

648 Reichardt, K. and Dourado-Neto, D. (2019) Ethylene production and physiological parameters

649 in common bean plants under water deficit. J. Agricult. Sci. 11, 301-310.

650 https://doi.org/10.5539/jas.v11n3p301

651 29. Omae, H., Kumar, A., Kashiwaba, K. and Shono, M. (2007) Assessing drought tolerance

652 of snap bean (Phaseolus vulgaris) from genotypic differences in leaf water relations, shoot

653 growth and photosynthetic parameters. Plant Prod. Sci. 10, 28-35.

654 https://doi.org/10.1626/pps.10.28.

655 30. Robson, T. M., Klem, K., Urban, O. and Jansen, M. A. K. (2015) Re-interpreting plant

656 morphological responses to UV-B radiation. Plant, Cell Environ. 38, 856-866.

657 https://doi.org/10.1111/pce.12374.

658 31. Cen, Y. P. and Bornman, J. F. (1993) The effect of exposure to enhanced UV-B radiation 
659 on the penetration of monochromatic and polychromatic UV-B radiation in leaves of Brassica napus. Physiol. Plant. 87, 249-255. https://doi.org/10.1111/j.1399-3054.1993.tb01727.x.

32. Gonzalez, R., Paul, N. D., Percy, K., Ambrose, M., McLaughlin, C. K., Barnes, J. D., Areses, M. and Wellburn, A. R. (1996) Responses to ultraviolet-B radiation (280-315 nm) of pea (Pisum sativum) lines differing in leaf surface wax. Physiol. Plant. 98, 852-860. https://doi.org/10.1111/j.1399-3054.1996.tb06695.x.

33. Qaderi, M. M. and Reid, D. M. (2005) Growth and physiological responses of canola (Brassica napus) to UV-B and $\mathrm{CO}_{2}$ under controlled environment conditions. Physiol. Plant. 125, 247-259. https://doi.org/10.1111/j.1399-3054.2005.00566.x.

34. Kim, K. S., Park, S. H. and Jenks, M. A. (2007) Changes in leaf cuticular waxes of sesame (Sesamum indicum L.) plants exposed to water deficit. J. Plant Physiol. 164, 1134-1143. https://doi.org/10.1016/j.jplph.2006.07.004.

35. Shepherd, T. and Griffiths, D. W. (2006) The effects of stress on plant cuticular waxes. New Phytol. 171, 469-499. https://doi.org/10.1111/j.1469-8137.2006.01826.x. Leaf Cuticular Waxes of Soybean (Glycine max [L.] Merr.). Int. J. Plant Sci. 168, 307-316. 37. Jenks, M. A., Andersen, L., Teusink, R. S. and Williams, M. H. (2001) Leaf cuticular waxes of potted rose cultivars as affected by plant development, drought and paclobutrazol treatments. Physiol. Plant. 112, 62-70. https://doi.org/10.1034/j.1399-3054.2001.1120109.x. 38. Sánchez, F. J., Manzanares, M., De Andrés, E. F., Tenorio, J. L. and Ayerbe, L. (2001) Residual transpiration rate, epicuticular wax load and leaf colour of pea plants in drought conditions. Influence on harvest index and canopy temperature. Eur. J. Agron. 15, 57-70. https://doi.org/10.1016/S1161-0301(01)00094-6. 
682 39. Qaderi, M. M., Basraon, N. K., Chinnappa, C. C. and Reid, D. M. (2010) Combined

683 Effects of Temperature, Ultraviolet-B Radiation, and Watering Regime on Growth and

684 Physiological Processes in Canola (Brassica napus) Seedlings. Int. J. Plant Sci. 171, 466-481.

685 https://doi.org/10.1086/652389.

686 40. Qaderi, M. M., Reid, D. M. and Yeung, E. C. (2007) Morphological and physiological

687 responses of canola (Brassica napus) siliquas and seeds to $\mathrm{UVB}$ and $\mathrm{CO}_{2}$ under controlled

688 environment conditions. Environ. Exp. Bot. 60, 428-437.

$689 \mathrm{https} / / /$ doi.org/10.1016/j.envexpbot.2006.12.019.

690 41. Gordon, D. C., Percy, K. E. and Riding, R. T. (1998) Effects of UV-B Radiation on

691 Epicuticular Wax Production and Chemical Composition of Four Picea Species. New Phytol.

$692 \mathbf{1 3 8}, 441-449$.

693 42. Day, T. A., Vogelmann, T. C. and DeLucia, E. H. (1992) Are some plant life forms more

694 effective than others in screening out ultraviolet-B radiation? Oecologia 92, 513-519.

695 43. Holmes, M. G. and Keiller, D. R. (2002) Effects of pubescence and waxes on the

696 reflectance of leaves in the ultraviolet and photosynthetic wavebands: a comparison of a range

697 of species. Plant, Cell Environ. 25, 85-93. https://doi.org/10.1046/j.1365-3040.2002.00779.x.

698 44. Oliveira, A. F. M., Meirelles, S. T. and Salatino, A. (2003) Epicuticular waxes from

699 caatinga and cerrado species and their efficiency against water loss. An. Acad. Bras. Cienc. 75,

700 431-439. https://doi.org/10.1590/S0001-37652003000400003.

701 45. Sousa, R. F. and Sousa, J. A. (2017) Metabólicos secundários associados a estresse hídrico

702 e suas funções nos tecidos vegetais. Rev. Bras. Gestão Ambient. 11, 1-8.

703 46. Dinakar, C., Djilianov, D. and Bartels, D. (2012) Photosynthesis in desiccation tolerant

704 plants: energy metabolism and antioxidative stress defense. Plant Sci. 182, 29-41. 
705 https://doi.org/10.1016/j.plantsci.2011.01.018.

706 47. Singh, S., Agrawal, S. B. and Agrawal, M. (2015) Responses of pea plants to elevated UV-

707 B radiation at varying nutrient levels: N-metabolism, carbohydrate pool, total phenolics and

708 yield. Funct. Plant Biol. 42, 1045-1056. https://doi.org/10.1071/FP15003.

709 48. Musil, C. F., Chimphango, S. B. M. and Dakora, F. D. (2002) Effects of elevated

710 ultraviolet-B radiation on native and cultivated plants of southern Africa. Ann. Bot. 90, $127-$

711 137. https://doi.org/10.1093/aob/mcf156.

712 49. Tsoata, E., Temegne Nono, C. and Youmbi, E. (2017) Analysis of early biochemical

713 criterion to screen four Fabaceae plants for their tolerance to drought stress. Int. J. Curr. Res.

$7149,44568-44575$.

715 50. Muller, B., Pantin, F., Génard, M., Turc, O., Freixes, S., Piques, M. and Gibon, Y. (2011)

716 Water deficits uncouple growth from photosynthesis, increase C content, and modify the

717 relationships between C and growth in sink organs. J. Exp. Bot. 62, 1715-1729.

718 https://doi.org/10.1093/jxb/erq438.

719 51. Andrade, E. R., Ribeiro, V. N., Azevedo, C. V. G., Chiorato, A. F., Williams, T. C. R. and

720 Carbonell, S. A. M. (2016) Biochemical indicators of drought tolerance in the common bean

721 (Phaseolus vulgaris L.). Euphytica 210, 277-289. https://doi.org/10.1007/s10681-016-1720-4.

722 52. Cekic, F. O. and Yilmaz, S. (2018) Combined stress induced GABA-mediated stress

723 signaling in bean plants.

724 53. Gharibi, S., Sayed Tabatabaei, B. E., Saeidi, G., Talebi, M. and Matkowski, A. (2019) The

725 effect of drought stress on polyphenolic compounds and expression of flavonoid biosynthesis

726 related genes in Achillea pachycephala Rech.f. Phytochemistry 162, 90-98.

727 https://doi.org/10.1016/j.phytochem.2019.03.004. 
728 54. Neugart, S. and Schreiner, M. (2018) UVB and UVA as eustressors in horticultural and

729 agricultural crops. Sci. Hortic. 234, 370-381. https://doi.org/10.1016/j.scienta.2018.02.021

730 55. Caliskan, O., Radusiene, J., Temizel, K. E., Staunis, Z., Cirak, C., Kurt, D. and Odabas, M.

731 S. (2017) The effects of salt and drought stress on phenolic accumulation in greenhouse-grown

732 Hypericum pruinatum. Ital. J. Agron. 12, 271-275. https://doi.org/10.4081/ija.2017.918.

733 56. Kunst, L. and Samuels, L. (2009) Plant cuticles shine: advances in wax biosynthesis and

734 export. Curr. Opin. Plant Biol. 12, 721-727. https://doi.org/10.1016/j.pbi.2009.09.009.

735 


\section{FIGURE CAPTIONS}

737 Figure 1. Non-metric multidimensional scaling ordination plots of means of growth and 738 biomass parameters and their 95\% confidence interval ranges for Phaseolus vulgaris L. cultivars 739 IAC Imperador (Imp) and IAC Milênio (Mil) submitted to four treatments (C: control, D: 740 drought, UVB: enhanced UV-B radiation, and UVB+D: enhanced UV-B radiation plus drought).

Figure 2. Growth and biomass data from Phaseolus vulgaris L. cultivars IAC Imperador and 743 IAC Milênio submitted to four treatments (C: control, D: drought, UVB: enhanced UV-B radiation, and $\mathbf{U V B}+\mathbf{D}$ : $\mathrm{UV}-\mathrm{B}$ plus drought). Data are presented as means \pm standard deviation.

745 For all treatments $n=10$, except UVB of Imperador $(n=9)$ and UVB $+D$ of Milênio $(n=6)$. Data

746 were compared among treatments for the same cultivar. Different letters represent significantly 747 different means $(P<0.05)$. *indicates significant differences among groups that were not 748 resolved in the post-hoc Dunn test.

Figure 3. Non-metric multidimensional scaling ordination plots of means and their $95 \%$ 751 confidence interval ranges of a) Waxes, b) Primary Metabolites, and c) Phenolics in Phaseolus 752 vulgaris L. cultivars IAC Imperador (Imp) and IAC Milênio (Mil) submitted to four treatments 753 (C: control, D: drought, UVB: enhanced UV-B radiation, and UVB+D: UV-B plus drought). 754 Means are depicted as squares (Imp) or circles (Mil).

Figure 4. Wax content and composition for leaves of Phaseolus vulgaris L. cultivars IAC

757 Imperador and IAC Milênio submitted to four treatments (C: control, D: drought, UVB: 
758 enhanced UV-B radiation, and UVB+D: UV-B plus drought). a) Wax content. Data are

759 presented as the mean \pm standard deviation. For all treatments $n=5$, except UVB-D of Milênio

$760(n=3)$ Data were compared among treatments for the same cultivar. Different letters represent

761 significantly different means $(P<0.05)$. b) Mean relative percentage of four major wax classes.

$762 \mathrm{NI}=$ not identified.

763

764 Figure 5. Content of primary metabolites ( $\mu \mathrm{g}$ of compound per $\mathrm{g}$ of fresh weight, $\mu \mathrm{g} \mathrm{g}^{-1} \mathrm{FW}$ ) of

765 leaves from Phaseolus vulgaris L. cultivars IAC Imperador and IAC Milênio submitted to four

766 treatments (C: control, D: drought, UVB: enhanced UV-B radiation, and UVB+D: UV-B plus

767 drought). Data are presented as means \pm standard deviation. For all treatments $n=5$, except UVB-

768 D of Milênio $(n=4)$. Data were compared among treatments for the same cultivar. Different

769 letters represent significantly different means $(P<0.05)$. For each class, the following

770 compounds of Table 2 were considered: total soluble sugars (compounds 11, 15, 16, 17, 18, 21,

771 and 23), total amino acids (compounds 3, 5, 6, 7 and 8) and total carboxylic acid (compounds 1,

7724,9 and 14).

773

Figure 6. Biosynthesis scheme associated with the heatmap of changes in 13 metabolites and 6

775 classes of compound levels in leaves from Phaseolus vulgaris L. cultivars IAC Imperador and

776 IAC Milênio in response to four treatments (C: control, D: drought, UVB: enhanced UV-B radiation, and UVB+D: UV-B plus drought). The $\log _{2}$ fold changes are shown in the heatmap results: Red indicates an increase in comparison to control, while blue indicates a decrease. 
Table 1. Relative percentage of leaf wax compounds detected by GC-MS of two cultivars (IAC Imperador and IAC Milênio) of Phaseolus vulgaris L. submitted to four treatments. Imperador: control $(\mathbf{C}, \mathrm{n}=5)$, drought $(\mathbf{D}, \mathrm{n}=5), \mathrm{UV}-\mathrm{B}(\mathbf{U V B}, \mathrm{n}=5)$, and UV-B plus drought $(\mathbf{U V B}+\mathbf{D}, \mathrm{n}=5)$. Milênio: control $(\mathbf{C}, \mathrm{n}=5)$, drought $(\mathbf{D}, \mathrm{n}=5)$, UV-B $(\mathbf{U V B}, \mathrm{n}=5)$, and UV-B plus drought $(\mathbf{U V B}+\mathbf{D}, \mathrm{n}=3)$.

\begin{tabular}{|c|c|c|c|c|c|c|c|c|}
\hline \multirow{2}{*}{$\begin{array}{c}\text { Cultivar } \\
\text { Treatment }\end{array}$} & \multicolumn{4}{|c|}{ Imperador } & \multicolumn{4}{|c|}{ Milênio } \\
\hline & $\mathbf{C}$ & D & UVB & UVB+D & $\mathrm{C}$ & D & UVB & UVB+D \\
\hline Total alkanes & $40.70 \pm 10.61^{b}$ & $52.25 \pm 11.96^{\mathrm{ab}}$ & $61.26 \pm 6.76^{a b}$ & $87.50 \pm 16.82^{a}$ & $33.50 \pm 10.95^{\mathrm{a}}$ & $33.36 \pm 14.01^{\mathrm{a}}$ & $40.56 \pm 15.53^{a}$ & $20.12 \pm 2.79^{a}$ \\
\hline $\mathrm{C}_{24}$ & 0.00 & 0.00 & $2.49 \pm 1.40$ & 0.00 & 0.00 & 0.00 & 0.00 & 0.00 \\
\hline $\mathrm{C}_{25}$ & 0.00 & 0.00 & $4.73 \pm 0.66$ & 0.00 & 0.00 & 0.00 & 0.00 & 0.00 \\
\hline $\mathrm{C}_{26}$ & 0.00 & 0.00 & $5.99 \pm 0.97$ & 0.00 & 0.00 & 0.00 & 0.00 & 0.00 \\
\hline $\mathrm{C}_{27}$ & $1.58 \pm 0.93$ & $3.58 \pm 2.25$ & $8.87 \pm 1.60$ & 0.00 & $0.24 \pm 0.53$ & $1.72 \pm 0.66$ & 0.00 & 0.00 \\
\hline $\mathrm{C}_{28}$ & $1.17 \pm 1.07$ & $3.63 \pm 2.41$ & $9.48 \pm 1.58$ & 0.00 & 0.00 & $1.67 \pm 0.60$ & 0.00 & 0.00 \\
\hline $\mathrm{C}_{29}$ & $13.14 \pm 1.82^{b}$ & $20.22 \pm 7.24^{\mathrm{ab}}$ & $13.25 \pm 2.23^{b}$ & $30.20 \pm 6.32^{a}$ & $17.79 \pm 7.37^{\mathrm{a}}$ & $12.65 \pm 4.64^{\mathrm{a}}$ & $17.81 \pm 7.62^{\mathrm{a}}$ & $8.81 \pm 1.49^{a}$ \\
\hline $\mathrm{C}_{30}$ & $1.11 \pm 1.02$ & $3.38 \pm 2.19$ & $6.58 \pm 1.11$ & 0.00 & 0.00 & $1.60 \pm 0.72$ & 0.00 & 0.00 \\
\hline $\mathrm{C}_{31}$ & $18.78 \pm 6.97^{a b}$ & $17.26 \pm 11.15^{a b}$ & $9.27 \pm 1.65^{b}$ & $57.30 \pm 12.93^{a}$ & $14.62 \pm 4.66^{\mathrm{a}}$ & $12.80 \pm 5.72^{\mathrm{a}}$ & $22.76 \pm 8.07^{\mathrm{a}}$ & $11.31 \pm 1.34^{\mathrm{a}}$ \\
\hline $\mathrm{C}_{32}$ & $0.71 \pm 0.97$ & 0.00 & $0.57 \pm 1.28$ & 0.00 & 0.00 & $0.41 \pm 0.91$ & 0.00 & 0.00 \\
\hline $\mathrm{C}_{33}$ & $4.22 \pm 2.47$ & $4.17 \pm 1.34$ & 0.00 & 0.00 & $0.86 \pm 1.38$ & $2.51 \pm 1.06$ & 0.00 & 0.00 \\
\hline $\begin{array}{l}\text { Total primary } \\
\text { alcohols }\end{array}$ & $57.63 \pm 7.57^{a}$ & $28.55 \pm 22.99^{a b}$ & $13.15 \pm 8.81^{\mathrm{ab}}$ & $9.53 \pm 15.71^{b}$ & $66.50 \pm 10.95^{\mathrm{a}}$ & $66.29 \pm 13.97^{\mathrm{a}}$ & $40.06 \pm 21.55^{a}$ & $65.50 \pm 6.52^{a}$ \\
\hline $\mathrm{C}_{24}$ & 0.00 & 0.00 & $0.50 \pm 1.13$ & 0.00 & 0.00 & 0.00 & $0.57 \pm 0.82$ & $0.60 \pm 1.04$ \\
\hline $\mathrm{C}_{26}$ & $38.31 \pm 5.44^{a}$ & $18.62 \pm 14.46^{a b}$ & $7.03 \pm 4.20^{b}$ & $5.53 \pm 9.11^{b}$ & $44.58 \pm 7.58^{\mathrm{a}}$ & $41.76 \pm 11.73^{a b}$ & $22.40 \pm 10.15^{b}$ & $40.84 \pm 5.94^{\mathrm{ab}}$ \\
\hline $\mathrm{C}_{28}$ & $19.32 \pm 2.81^{\mathrm{a}}$ & $9.52 \pm 8.24^{\mathrm{ab}}$ & $5.04 \pm 3.18^{\mathrm{ab}}$ & $4.00 \pm 6.60^{b}$ & $20.31 \pm 5.06^{\mathrm{a}}$ & $22.60 \pm 3.77^{\mathrm{a}}$ & $14.14 \pm 8.12^{\mathrm{a}}$ & $22.45 \pm 1.74^{\mathrm{a}}$ \\
\hline $\mathrm{C}_{30}$ & 0.00 & $0.40 \pm 0.90$ & $0.58 \pm 1.30$ & 0.00 & $0.75 \pm 1.04$ & $1.26 \pm 0.79$ & $1.64 \pm 2.27$ & $1.62 \pm 1.42$ \\
\hline $\mathrm{C}_{32}$ & 0.00 & 0.00 & 0.00 & 0.00 & $0.85 \pm 1.27$ & $0.68 \pm 1.00$ & $1.32 \pm 1.88$ & 0.00 \\
\hline Hexadecanoic acid & 0.00 & 0.00 & $0.56 \pm 1.25$ & 0.00 & 0.00 & 0.00 & $0.47 \pm 1.05$ & $2.10 \pm 1.82$ \\
\hline Total steroids & 0.00 & 0.00 & $2.96 \pm 4.16$ & $2.23 \pm 4.99$ & 0.00 & 0.00 & $6.41 \pm 4.24$ & $5.85 \pm 0.67$ \\
\hline Stigmasterol & 0.00 & 0.00 & $1.32 \pm 1.83$ & $2.23 \pm 4.99$ & 0.00 & 0.00 & $2.92 \pm 1.85$ & $1.98 \pm 1.74$ \\
\hline$\beta$-sitosterol & 0.00 & 0.00 & $1.64 \pm 2.33$ & 0.00 & 0.00 & 0.00 & $3.49 \pm 3.33$ & $3.86 \pm 1.36$ \\
\hline Not identified & $1.67 \pm 3.74$ & $19.20 \pm 23.40$ & $22.08 \pm 7.88$ & $0.74 \pm 1.01$ & 0.00 & $0.35 \pm 0.78$ & $12.49 \pm 15.87$ & $9.53 \pm 5.09$ \\
\hline
\end{tabular}

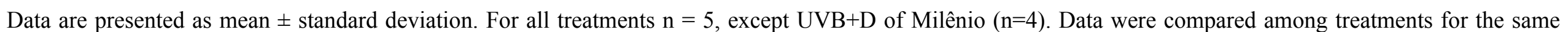

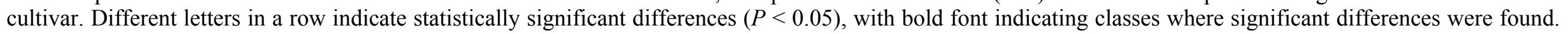
All $p$ values are in Table $\mathrm{S} 1$ of supplementary material. 
Table 2. Primary metabolites analyzed by GC-MS in leaves from two cultivars (IAC Imperador and IAC Milênio) of Phaseolus vulgaris L.

\begin{tabular}{|c|c|c|c|c|c|c|c|}
\hline Peak & RT (min) & Probable compounds & $\begin{array}{c}\text { Match } \\
\text { (NIST02) }\end{array}$ & LRI & $\begin{array}{c}\text { LRI } \\
\text { (Nagai et al. 2017) }\end{array}$ & $\begin{array}{c}\text { LRI } \\
\text { (Mass bank) }\end{array}$ & $\begin{array}{c}\text { LRI } \\
(\text { GMD })\end{array}$ \\
\hline 1 & 17.723 & Succinic acid (2TMS) & 937 & 1313.4 & 1314.1 & 1303.7 & 1310.7 \\
\hline 2 & 20.569 & NI & - & 1421.1 & - & - & - \\
\hline 3 & 20.610 & Aspartic acid (2TMS) & 896 & 1422.7 & 1423.9 & - & 1422.4 \\
\hline 4 & 22.198 & Malic acid (3TMS) & 935 & 1485.6 & 1484.9 & 1478.0 & 1479.3 \\
\hline 5 & 23.023 & 5-oxoproline (2TMS) & 909 & 1519.3 & 1519.7 & 1519.7 & 1521.7 \\
\hline 6 & 23.157 & GABA (3TMS) & 866 & 1524.9 & 1524.5 & 1526.6 & 1527.5 \\
\hline 7 & 23.315 & Glutamic acid (2TMS) & 784 & 1531.5 & 1531.4 & - & 1528.2 \\
\hline 8 & 25.319 & Glutamic acid (3TMS) & - & 1616.03 & - & 1607.8 & 1614.6 \\
\hline 9 & 25.684 & Tartaric acid (4TMS) & 929 & 1632.1 & - & 1620.9 & 1628.9 \\
\hline 10 & 27.544 & Ribitol (5TMS) - internal standard & 917 & 1715.0 & 1715.8 & 1710.9 & 1712.7 \\
\hline 11 & 28.406 & Ribonic acid (5TMS) & 741 & 1755.0 & - & - & 1751.5 \\
\hline 12 & 28.536 & NI & - & 1761.1 & - & - & - \\
\hline 13 & 28.846 & NI & - & 1775.5 & - & - & - \\
\hline 14 & 29.616 & Citric acid (4TMS) & 906 & 1811.9 & 1811.3 & 1803.9 & 1803.9 \\
\hline 15 & 30.619 & Fructose $O$-methyloxime (5TMS) ${ }^{1}$ & 903 & 1860.9 & 1861.3 & 1855.5 & 1853.9 \\
\hline 16 & 30.820 & Fructose $O$-methyloxime (5TMS) ${ }^{1}$ & 875 & 1870.7 & 1870.5 & 1864.3 & 1863.1 \\
\hline 17 & 31.123 & Glucose $O$-methyloxime (5TMS) ${ }^{2}$ & 948 & 1885.5 & 1885.4 & 1881.6 & 1880.5 \\
\hline 18 & 31.497 & Glucose $O$-methyloxime (5TMS) ${ }^{2}$ & 907 & 1904.0 & 1903.6 & 1898.5 & 1902.4 \\
\hline 19 & 31.969 & NI & - & 1928.1 & - & - & - \\
\hline 20 & 32.665 & NI & - & 1963.8 & - & - & - \\
\hline 21 & 34.826 & Myo-inositol (6TMS) & 922 & 2077.7 & 2076.0 & 2083.6 & 2080.2 \\
\hline 22 & 38.753 & NI & - & 2199.8 & - & - & - \\
\hline 23 & 43.762 & Sucrose (8TMS) & 880 & 2614.7 & - & 2614.8 & 2623.0 \\
\hline
\end{tabular}

RT: retention time. Match: NIST02 library. LRI: linear retention index. GMD: Golm Metabolome Database.

-: linear retention index not found in the database.

NI: not identified. TMS: trimethylsilyl. GABA: gamma-aminobutyric acid.

${ }^{1}$ Fructose stereoisomers produced by methoximation reaction.

${ }^{2}$ Glucose stereoisomers produced by methoximation reaction. 
Table 3. Concentration of primary metabolites ( $\mu \mathrm{g}$ of compound/g of fresh plant, $\mu \mathrm{g} \mathrm{g}^{-1} \mathrm{FW}$ ) detected by GC-MS in leaves of Phaseolus vulgaris L. cultivar IAC Imperador submitted to four treatments: control $(\mathbf{C}, n=5)$, drought $(\mathbf{D}, \mathrm{n}=5), \mathrm{UV}-\mathrm{B}(\mathbf{U V B}, \mathrm{n}=5)$, and UV-B plus drought $(\mathbf{U V B}+\mathbf{D}$, $\mathrm{n}=5)$.

\begin{tabular}{|c|c|c|c|c|c|}
\hline \multirow{2}{*}{ Peak } & \multirow{2}{*}{ Probable compounds } & \multicolumn{4}{|c|}{ Treatments } \\
\hline & & $\mathrm{C}$ & D & UVB & UVB+D \\
\hline 1 & Succinic acid (2TMS) & $11.81 \pm 26.41$ & $9.20 \pm 20.58$ & 0.00 & $34.00 \pm 34.17$ \\
\hline 2 & NI & $91.60 \pm 43.50^{\mathrm{a}}$ & $64.78 \pm 7.21^{\mathrm{a}}$ & $114.17 \pm 91.60^{\mathrm{a}}$ & $112.94 \pm 21.90^{\mathrm{a}}$ \\
\hline 3 & Aspartic acid (2TMS) & 0.00 & 0.00 & 0.00 & $47.60 \pm 5.36$ \\
\hline 4 & Malic acid (3TMS) & $559.66 \pm 215.99^{a b}$ & $413.56 \pm 27.51^{b}$ & $249.18 \pm 262.49^{b}$ & $867.98 \pm 243.80^{a}$ \\
\hline 5 & 5-oxoproline (2TMS) & $90.95 \pm 22.83^{a b}$ & $120.44 \pm 46.31^{a}$ & $26.91 \pm 37.94^{b}$ & $84.88 \pm 24.69^{a b}$ \\
\hline 6 & GABA (3TMS) & 0.00 & 0.00 & $18.85 \pm 26.44$ & $27.83 \pm 45.44$ \\
\hline $7-8$ & Glutamic acid ${ }^{1}$ & $92.14 \pm 20.35^{a b}$ & $133.39 \pm 47.52^{\mathrm{a}}$ & $23.87 \pm 36.07^{b}$ & $147.72 \pm 42.31^{\mathrm{a}}$ \\
\hline 9 & Tartaric acid (4TMS) & $7.63 \pm 17.06$ & $24.26 \pm 22.94$ & 0.00 & $85.30 \pm 90.85$ \\
\hline 11 & Ribonic acid (5TMS) & 0.00 & $5.11 \pm 11.43$ & 0.00 & $32.29 \pm 4.38$ \\
\hline 12 & NI & $38.72 \pm 54.24$ & $66.51 \pm 61.84$ & 0.00 & $62.33 \pm 60.45$ \\
\hline 13 & NI & $158.20 \pm 97.57^{b}$ & $217.89 \pm 38.74^{\mathrm{ab}}$ & $259.59 \pm 57.87^{a b}$ & $309.19 \pm 82.39^{a}$ \\
\hline 14 & Citric acid (4TMS) & $69.53 \pm 47.24$ & $116.26 \pm 57.96$ & 0.00 & $221.57 \pm 111.07$ \\
\hline $15-16$ & Fructose $O$-methyloxime (5TMS) ${ }^{1}$ & $267.76 \pm 163.11^{\mathrm{a}}$ & $197.31 \pm 162.97^{\mathrm{a}}$ & $152.75 \pm 69.00^{\mathrm{a}}$ & $168.65 \pm 61.06^{\mathrm{a}}$ \\
\hline $17-18$ & Glucose $O$-methyloxime (5TMS) ${ }^{2}$ & $517.10 \pm 506.79^{a}$ & $236.16 \pm 230.44^{\mathrm{a}}$ & $226.91 \pm 90.82^{\mathrm{a}}$ & $335.36 \pm 217.22^{\mathrm{a}}$ \\
\hline 19 & NI & 0.00 & 0.00 & $19.87 \pm 44.43$ & $94.65 \pm 20.45$ \\
\hline 20 & NI & $306.72 \pm 73.67^{\mathrm{a}}$ & $307.50 \pm 107.59^{a}$ & $263.61 \pm 45.87^{\mathrm{a}}$ & $361.98 \pm 79.47^{\mathrm{a}}$ \\
\hline 21 & Myo-inositol (6TMS) & $939.06 \pm 259.57^{\mathrm{a}}$ & $843.76 \pm 283.97^{\mathrm{a}}$ & $718.99 \pm 71.18^{\mathrm{a}}$ & $1098.09 \pm 210.07^{\mathrm{a}}$ \\
\hline 22 & NI & 0.00 & $13.47 \pm 30.11$ & $126.19 \pm 97.34$ & $184.27 \pm 228.34$ \\
\hline 23 & Sucrose (8TMS) & $672.26 \pm 534.17^{\mathrm{a}}$ & $905.05 \pm 353.53^{\mathrm{a}}$ & $838.21 \pm 147.71^{\mathrm{a}}$ & $1377.96 \pm 333.25^{\mathrm{a}}$ \\
\hline
\end{tabular}

NI: not identified. TMS: trimethylsilyl. GABA: gamma-aminobutyric acid.

Data are presented as mean \pm standard deviation.

Only compounds with letters were statistically analyzed. Different letters within a row indicate statistically significant differences $(P<0.05)$.

${ }^{1}$ Glutamic acid content corresponds to the sum of glutamic acid 2TMS and glutamic acid 3TMS.

${ }^{2}$ Fructose content corresponds to the sum of the two stereoisomers.

${ }^{3}$ Glucose content corresponds to the sum of the two stereoisomers.

All $p$ values are in Table $\mathrm{S} 1$ of supplementary material. 
Table 4. Concentration of primary metabolites ( $\mu \mathrm{g}$ of compound/g of fresh plant, $\mu \mathrm{g} \mathrm{g}^{-1} \mathrm{FW}$ ) detected by GC-MS in leaves of Phaseolus vulgaris L. cultivar IAC Milênio submitted to four treatments: control $(\mathbf{C}, \mathrm{n}=5)$, drought $(\mathbf{D}, \mathrm{n}=5)$, UVB $(\mathbf{U V B}, \mathrm{n}=5)$, and UVB plus drought $(\mathbf{U V B}+\mathbf{D}, \mathrm{n}=4)$.

\begin{tabular}{|c|c|c|c|c|c|}
\hline \multirow{2}{*}{ Peak } & \multirow{2}{*}{ Probable compounds } & \multicolumn{4}{|c|}{ Treatments } \\
\hline & & $\mathrm{C}$ & D & UVB & UVB+D \\
\hline 1 & Succinic acid (2TMS) & $7.59 \pm 16.98^{\mathrm{a}}$ & $16.80 \pm 23.11^{\mathrm{a}}$ & $29.64 \pm 44.38^{\mathrm{a}}$ & $41.90 \pm 1.88^{\mathrm{a}}$ \\
\hline 2 & NI & $97.29 \pm 47.44^{\mathrm{a}}$ & $76.56 \pm 42.22^{\mathrm{a}}$ & $60.94 \pm 23.31^{\mathrm{a}}$ & $77.16 \pm 33.93^{a}$ \\
\hline 3 & Aspartic acid (2TMS) & 0.00 & 0.00 & $11.79 \pm 26.37$ & $32.23 \pm 40.78$ \\
\hline 4 & Malic acid (3TMS) & $664.14 \pm 266.81^{a}$ & $764.66 \pm 496.43^{a}$ & $580.09 \pm 165.99^{a}$ & $771.78 \pm 287.82^{a}$ \\
\hline 5 & 5-oxoproline (2TMS) & $78.75 \pm 65.57^{\mathrm{a}}$ & $74.88 \pm 19.26^{\mathrm{a}}$ & $57.10 \pm 38.07^{\mathrm{a}}$ & $66.66 \pm 13.93^{\mathrm{a}}$ \\
\hline 6 & GABA (3TMS) & 0.00 & 0.00 & $17.27 \pm 23.78$ & $37.51 \pm 30.00$ \\
\hline $7-8$ & Glutamic acid ${ }^{1}$ & $23.12 \pm 32.17^{\mathrm{a}}$ & $40.81 \pm 38.64^{\mathrm{a}}$ & $80.52 \pm 63.02^{\mathrm{a}}$ & $36.96 \pm 44.59^{a}$ \\
\hline 9 & Tartaric acid (4TMS) & $74.14 \pm 39.75^{\mathrm{a}}$ & $39.83 \pm 62.80^{\mathrm{a}}$ & $43.00 \pm 30.11^{\mathrm{a}}$ & $58.01 \pm 16.69^{\mathrm{a}}$ \\
\hline 11 & Ribonic acid (5TMS) & $5.73 \pm 12.82^{\mathrm{a}}$ & $6.05 \pm 13.53^{\mathrm{a}}$ & $19.76 \pm 18.06^{\mathrm{a}}$ & $16.23 \pm 18.79^{a}$ \\
\hline 12 & NI & 0.00 & 0.00 & 0.00 & $16.15 \pm 36.11$ \\
\hline 13 & NI & $112.50 \pm 106.33^{a}$ & $172.60 \pm 73.04^{\mathrm{a}}$ & $233.94 \pm 79.13^{\mathrm{a}}$ & $215.92 \pm 36.28^{\mathrm{a}}$ \\
\hline 14 & Citric acid (4TMS) & $39.14 \pm 37.57^{\mathrm{a}}$ & $34.76 \pm 47.76^{\mathrm{a}}$ & $72.48 \pm 50.38^{a}$ & $115.41 \pm 85.60^{\mathrm{a}}$ \\
\hline $15-16$ & Fructose $O$-methyloxime (5TMS) ${ }^{2}$ & $175.45 \pm 138.98^{a}$ & $247.80 \pm 101.96^{\mathrm{a}}$ & $131.42 \pm 107.01^{\mathrm{a}}$ & $225.38 \pm 187.54^{\mathrm{a}}$ \\
\hline $17-18$ & Glucose $O$-methyloxime (5TMS) ${ }^{3}$ & $172.23 \pm 156.01^{\mathrm{a}}$ & $365.65 \pm 152.09^{a}$ & $154.46 \pm 139.35^{\mathrm{a}}$ & $424.43 \pm 475.73^{\mathrm{a}}$ \\
\hline 19 & NI & 0.00 & 0.00 & $39.00 \pm 54.12$ & $43.19 \pm 51.18$ \\
\hline 20 & $\mathrm{NI}$ & $213.17 \pm 72.34^{\mathrm{a}}$ & $232.30 \pm 15.34^{\mathrm{a}}$ & $193.47 \pm 33.36^{\mathrm{a}}$ & $254.75 \pm 117.48^{\mathrm{a}}$ \\
\hline 21 & Myo-inositol (6TMS) & $421.55 \pm 269.31^{\mathrm{a}}$ & $981.20 \pm 415.90^{\mathrm{a}}$ & $959.36 \pm 336.28^{a}$ & $980.58 \pm 348.82^{\mathrm{a}}$ \\
\hline 22 & NI & 0.00 & 0.00 & $83.28 \pm 119.70$ & $140.53 \pm 163.72$ \\
\hline 23 & Sucrose (8TMS) & $419.46 \pm 155.55^{b}$ & $646.77 \pm 269.63^{a b}$ & $619.34 \pm 150.05^{a b}$ & $1320.27 \pm 759.66^{2}$ \\
\hline
\end{tabular}

NI: not identified. TMS: trimethylsilyl. GABA: gamma-aminobutyric acid.

Data are presented as mean \pm standard deviation.

Only compounds with letters were statistically analyzed. Different letters within a row indicate statistically significant differences $(P<0.05)$.

${ }^{1}$ Glutamic acid content corresponds to the sum of glutamic acid 2TMS and glutamic acid 3TMS.

${ }^{2}$ Fructose content corresponds to the sum of the two stereoisomers.

${ }^{3}$ Glucose content corresponds to the sum of the two stereoisomers.

All $p$ values are in Table $\mathrm{S} 1$ of supplementary material. 


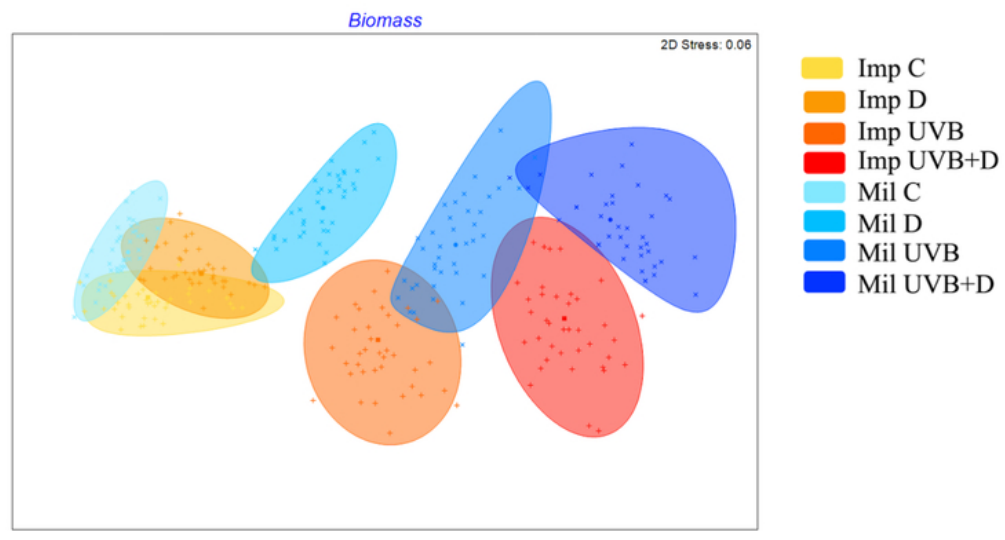

Figure 1. Non-metric multidimensional scaling ordination plots of means of growth and biomass parameters and their 95\% confidence interval ranges for Phaseolus vulgaris L. cultivars IAC Imperador (Imp) and IAC Milênio (Mil) submitted to four treatments (C: control, D: drought, UVB: enhanced UV-B radiation, and UVB+D: enhanced UV-B radiation plus drought). 
a

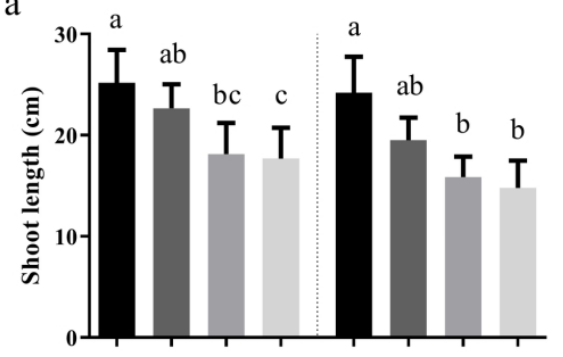

b

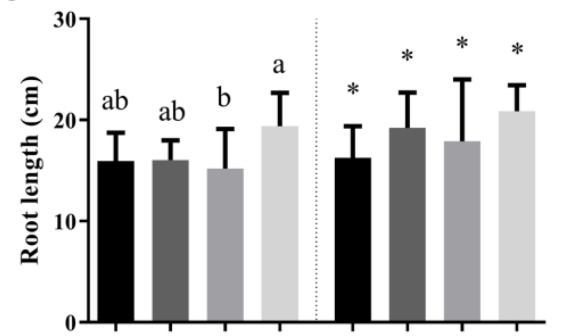

c

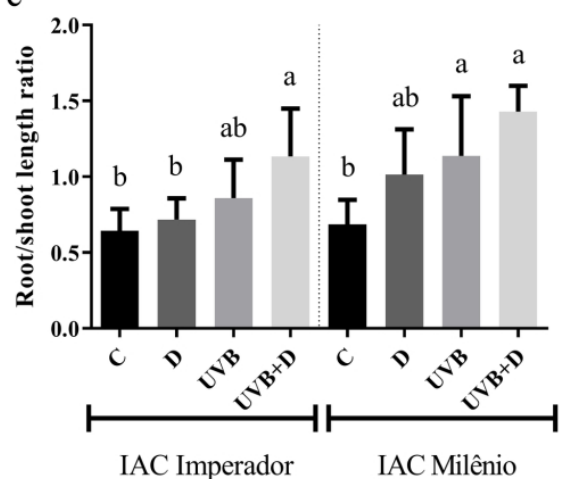

d

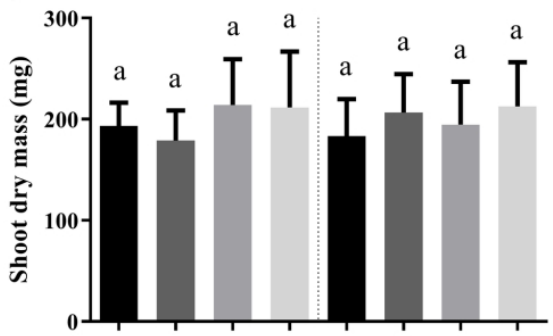

e

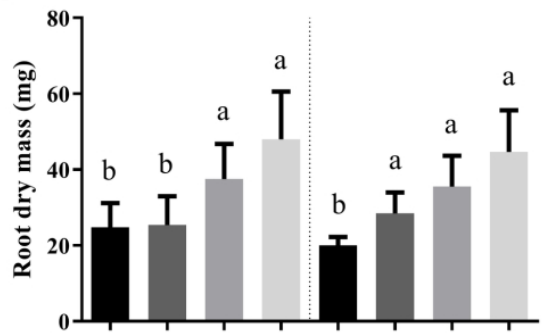

$\mathrm{f}$

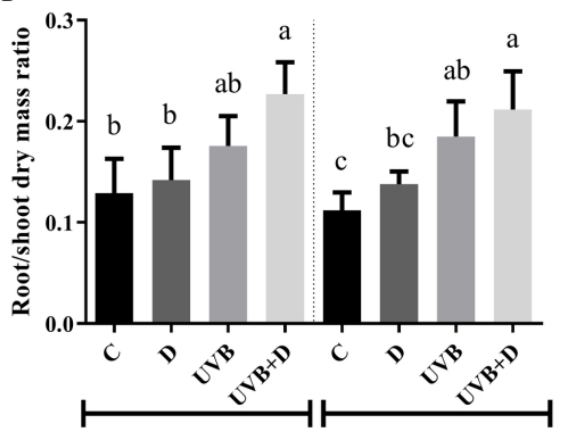

IAC Imperador

IAC Milênio

Figure 2. Growth and biomass data from Phaseolus vulgaris L. cultivars IAC Imperador and IAC Milênio submitted to four treatments ( $C$ : control, D: drought, UVB: enhanced UV-B radiation, and UVB+D: UV-B plus drought). Data are presented as means \pm standard deviation. For all treatments $n=10$, except UVB of Imperador $(n=9)$ and UVB+D of Milênio $(n=6)$. Data were compared among treatments for the same cultivar. Different letters represent significantly different means $(P<0.05)$. *indicates significant differences among groups that were not resolved in the post-hoc Dunn test. 

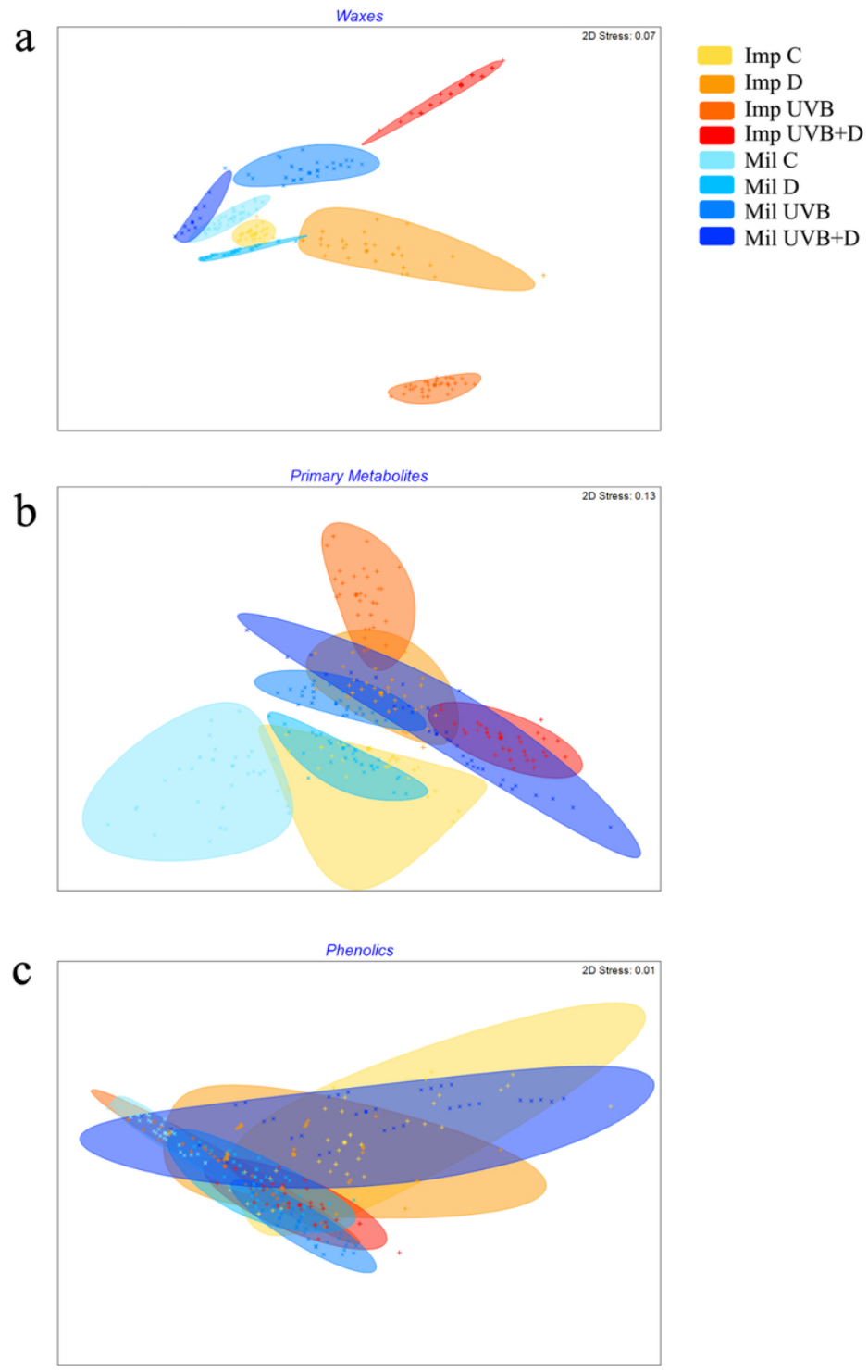

Figure 3. Non-metric multidimensional scaling ordination plots of means and their $95 \%$ confidence interval ranges of a) Waxes, b) Primary Metabolites, and c) Phenolics in Phaseolus vulgaris L. cultivars IAC Imperador (Imp) and IAC Milênio (Mil) submitted to four treatments (C: control, D: drought, UVB: enhanced UV-B radiation, and UVB+D: UV-B plus drought). Means are depicted as squares (Imp) or circles (Mil).

$80 \times 109 \mathrm{~mm}(300 \times 300 \mathrm{DPI})$ 
a

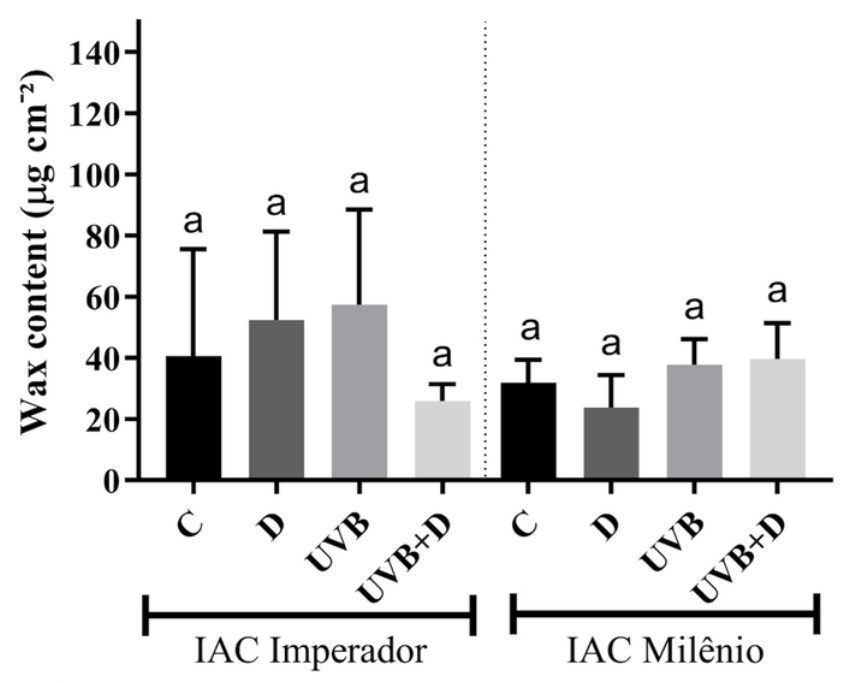

b

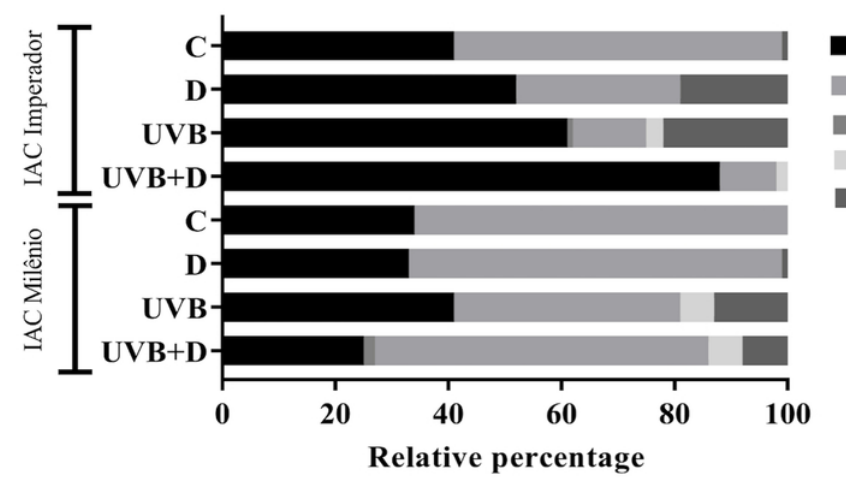

- Alkanes

Primary alcohols

- Hexadecanoid acid

- Steroids

$\mathrm{NI}$

Figure 4. Wax content and composition for leaves of Phaseolus vulgaris L. cultivars IAC Imperador and IAC Milênio submitted to four treatments ( $C$ : control, D: drought, UVB: enhanced UV-B radiation, and UVB+D:

UV-B plus drought). a) Wax content. Data are presented as the mean \pm standard deviation. For all treatments $n=5$, except UVB-D of Milênio $(n=3)$ Data were compared among treatments for the same cultivar. Different letters represent significantly different means $(P<0.05)$. b) Mean relative percentage of four major wax classes. NI = not identified. 


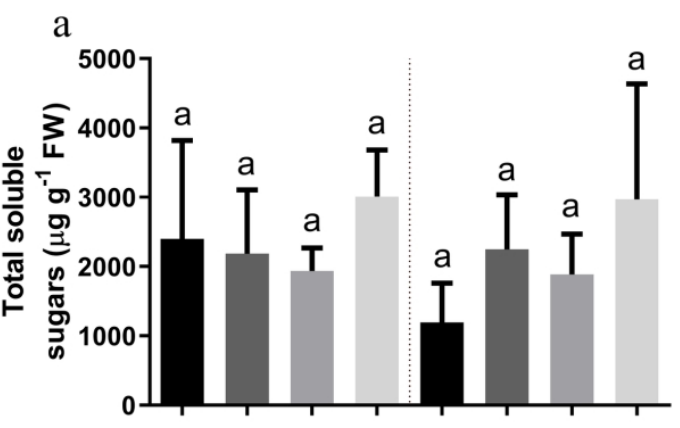

$\mathrm{b}$

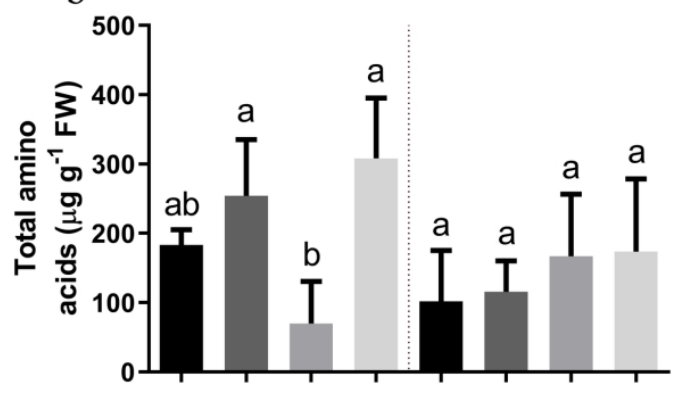

C

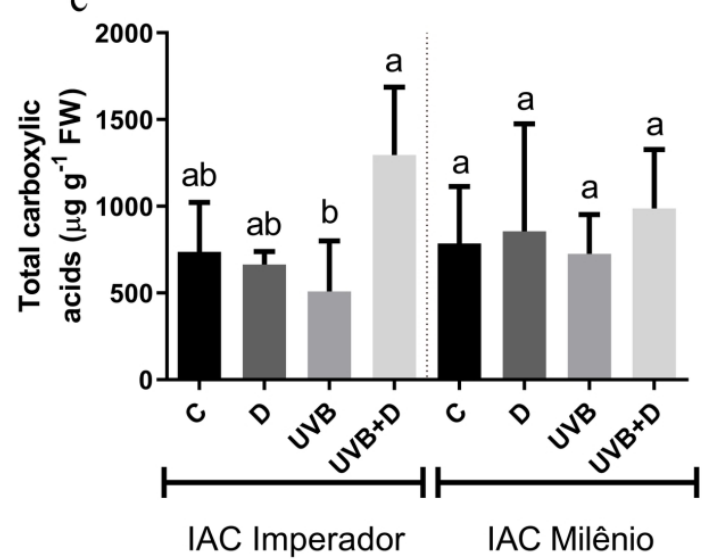

Figure 5. Content of primary metabolites ( $\mu \mathrm{g}$ of compound per $\mathrm{g}$ of fresh weight, $\mu \mathrm{g} \mathrm{g}-1 \mathrm{FW}$ ) of leaves from Phaseolus vulgaris L. cultivars IAC Imperador and IAC Milênio submitted to four treatments (C: control, D: drought, UVB: enhanced UV-B radiation, and UVB+D: UV-B plus drought). Data are presented as means \pm standard deviation. For all treatments $n=5$, except UVB-D of Milênio $(n=4)$. Data were compared among treatments for the same cultivar. Different letters represent significantly different means $(P<0.05)$. For each class, the following compounds of Table 2 were considered: total soluble sugars (compounds 11, 15, $16,17,18,21$, and 23), total amino acids (compounds 3, 5, 6, 7 and 8) and total carboxylic acid (compounds 1, 4, 9 and 14). 


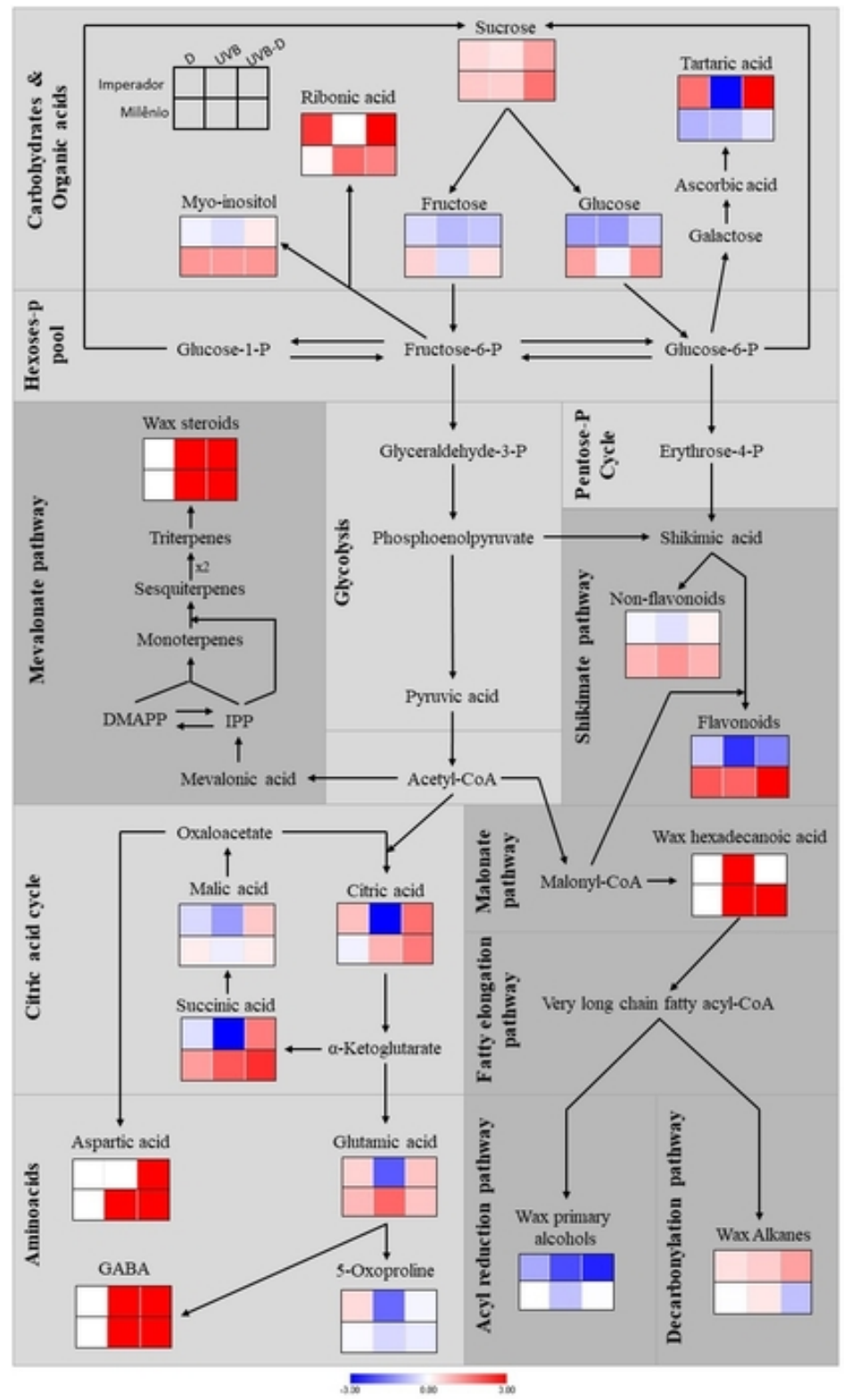

Figure 6. Biosynthesis scheme associated with the heatmap of changes in 13 metabolites and 6 classes of compound levels in leaves from Phaseolus vulgaris L. cultivars IAC Imperador and IAC Milênio in response to four treatments (C: control, D: drought, UVB: enhanced UV-B radiation, and UVB+D: UV-B plus drought). The log2 fold changes are shown in the heatmap results: Red indicates an increase in comparison to control, while blue indicates a decrease. 